Revista lus et Praxis, Año 24, No 1, 2018, pp. 397 - 436

ISSN 0717 - 2877

Universidad de Talca - Facultad de Ciencias Jurídicas y Sociales

Igual de diferentes: la identidad de género de niñas, niños y adolescentes en Chile

Isaac Ravetllat Ballesté

Trabajo recibido el 28 de marzo de 2018 aprobado el 30 de mayo de 2018

\title{
Igual de diferentes: la identidad de género de niñas, niños y adolescentes en Chile*
}

EqualLy DifFERENT: THE GENDER IDENTITY OF CHILDREN IN CHILE

\author{
IsaAc RavetLlat Ballesté**
}

\begin{abstract}
RESUMEN
En los últimos tiempos estamos asistiendo a la emergencia de nuevas realidades en el interior del colectivo trans*, a dar visibilidad a situaciones o circunstancias que hasta hace pocos años eran completamente invisibles y absolutamente silenciadas. Este es el caso, sin ir más lejos, de la cuestión de la transexualidad en la infancia y la adolescencia. Pareciera que estamos viviendo los momentos iniciales del que está llamado a ser un cambio de paradigma: el dejar de entender la experiencia de las niñas, niños y adolescentes trans* como una patología, como un desorden identitario o un problema, y pasar a considerarlo como un conjunto de construcciones y elecciones de carácter personalísimo, de trayectorias heterogéneas, fluidas y cambiantes, a las que la ley no debe ni puede darles la espalda. Es por ello que en el presente artículo analizaremos el contexto social y legal que rodea la vida de las niñas, niños y adolescentes trans* en el Chile actual, haciendo particular incidencia en aquellos aspectos que caracterizan el derecho a la identidad (de género) en aquellos casos en que su titularidad recae en una persona menor de edad.
\end{abstract}

\section{ABSTRACT}

In recent times we are witnessing the emergence of new realities within the trans* collective, giving visibility to situations or circumstances that until a few years ago were completely invisible and absolutely silenced. This is the case, without going further, of the question of trans-sexuality in childhood and adolescence. It seems that we are living the initial moments of what is called to be a paradigm shift: the failure to understand the experience of trans children and adolescents as a pathology, as an identity disorder or problem, and to consider it as a set of constructions and

\footnotetext{
* Este trabajo se enmarca en el Proyecto de Investigación Fondecyt № 11150135, relativo a "La irrupción, configuración y desarrollo del concepto jurídico indeterminado del interés superior del niño en el Derecho Civil chileno a la luz de la Convención sobre los Derechos del Niño", del cual el autor es investigador responsable.

** Profesor Asociado de Derecho Privado de la Facultad de Ciencias Jurídicas y Sociales de la Universidad de Talca, Chile. Doctor en Derecho por la Universidad de Barcelona, España. Subdirector del Centro de Estudios sobre los Derechos de la Infancia y la Adolescencia de la Universidad de Talca. Secretario General de la Asociación para la Defensa de los Derechos de la Infancia y la Adolescencia (ADDIA). Vocal del Observatorio de Infancia del Gobierno de la Generalitat de Cataluña, España. Correo electrónico: iravetllat@utalca.cl.
} 
choices of a very personal character, with heterogeneous, fluid and changing trajectories, to which the law should not turn away. It is for this reason that in this article we analyse the social and legal context that surrounds the lives of children and adolescents trans* in Chile, with particular emphasis on those aspects that characterize the right to (gender) identity in those cases where their ownership is a minor.

Palabras Clave

Transgénero, identidad y expresión de género, infancia y adolescencia.

KEY WORDS

Transgender, gender identity, childhood and adolescence.

\section{Introducción}

La transexualidad es un fenómeno presente en todas las culturas de la humanidad y en todo tiempo histórico. Las manifestaciones de identidad de género del ser humano son variadas y cada cultura hace su propia interpretación de esta circunstancia. Las respuestas que las distintas sociedades han dado a esta realidad humana han sido muy diversas a lo largo del tiempo y en las distintas geografías de nuestro mundo'. Algunas comunidades han aceptado en su seno una realidad de género no estrictamente binaria y han articulado mecanismos sociales y normas legales que promueven la plena integración de las personas trans $^{* 2}$ en su contexto de vida cotidiano. Otras, en cambio, han manifestado diversos grados de rechazo y represión de las expresiones de identidad de género provocando importantes vulneraciones de los derechos humanos de las personas trans*3.

La definición del género de una persona va mucho más allá de la simple apreciación visual de sus órganos genitales externos en el momento de su

1 Platero (2014a), p. 184 y Platero (2014b), p. 27.

2 En el texto usaremos preferentemente el término "trans*" con un asterisco, como un concepto paraguas que puede incluir diferentes expresiones e identidades de género, tales como: trans, transexual, transgénero. Lo que el asterisco añade es señalar la heterogeneidad a la hora de concebir el cuerpo, la identidad y las vivencias que van más allá de las normas sociales binarias impuestas. Toda esta terminología tiene en común ser autoelegida por sus protagonistas, frente a aquella que proviene y es impuesta por el ámbito médico y que señala una patología. El asterisco quiere especificar que se pueden librar luchas comunes, al tiempo que reconocer que hay muchas otras cuestiones en las que no hay un consenso o una única visión de lo que supone ser una persona trans.

3 Tal y como nos recuerda el Ministerio de Salud de la Nación Argentina, el denominado estrés de las minorías está vinculado a los procesos de minorización de identidades que son percibidas fuera de las normas sociales y la cultura hegemónicas. Estos procesos sirven como sustento de diversas formas de discriminación, estigmatización, invisibilización, subordinación y violencia. Si bien la idea de minoría puede remitirnos a lo cuantitativo, debemos tener en cuenta el aspecto cualitativo del concepto. En este sentido, el concepto minorías viene a enfatizar el carácter sociocultural de un proceso que, más allá de cuestiones estadísticas, construye minorías como una forma de crear fronteras con el otro en el marco de diferentes relaciones de poder. Confróntese, Ministerio de SAlud de la Nación Argentina (2017), p. 26. 
nacimiento, y de acuerdo con lo expresado tanto por la Corte Interamericana de Derechos Humanos ${ }^{4}$ como por el Tribunal Europeo de Derechos Humanos ${ }^{5}$, no es un concepto puramente biológico, sino, y ante todo, psicosocial.

Ciertamente, en todo individuo imperan las características psicosociológicas que configuran su verdadera forma de ser y debe otorgarse soberanía a la voluntad humana sobre cualquier otra consideración física. La libre determinación del género de cada sujeto ha de ser afirmada como un derecho humano fundamental, parte inescindible de su derecho al libre desarrollo de la personalidad6.

Las personas trans* en nuestro país están protagonizando una larga lucha para conseguir desarrollarse socialmente en el género al que entienden pertenecer. Las dificultades que se encuentran en este proceso son innumerables y de toda índole, y el sufrimiento padecido es considerable 7 . Es necesario, pues, de una vez por todas, crear un marco normativo claro que facilite este proceso de tránsito, permitiendo la progresiva adaptación de la persona y el desarrollo completo de sus potencialidades humanas ${ }^{8}$.

Pues bien, si al desconocimiento generalizado, invisibilidad y situación de vulnerabilidad que vive el colectivo trans*, le sumamos, además, un segundo elemento estigmatizador, cual es el ser una persona menor de edad, la negativa al reconocimiento de su derecho a la identidad o la desatención a sus necesidades de afirmación, se multiplican de manera exponencial ${ }^{9}$.

\footnotetext{
${ }^{4}$ Opinión Consultiva OC/17, sobre identidad de género, e igualdad y no discriminación a parejas del mismo sexo, de 24 de noviembre de 2017, párrafo 32.

${ }^{5}$ El Tribunal Europeo de Derechos Humanos, caso Christine Goodwin vs. Reino Unido, sentencia de 11 de julio de 2002, párrafos 81-83, 100, considera que para determinar el sexo de la persona, no se debe atender únicamente al sexo biológico/cromosómico, sino que también deben tomarse en consideración otros criterios, entre ellos el del sexo cerebral.
}

${ }^{6}$ SUESS (2010), p. 39.

7 Un hito para Chile fue la aprobación de la Ley № 20.609, de 24 de julio de 2012, que establece medidas contra la discriminación, haciéndose mención expresa en su artículo $2^{\circ}$ a la identidad de género. Para un análisis crítico del texto de la mentada norma -conocida vulgarmente como Ley Zamudio-, confrontarlo con Gauché (2014), pp. 11-58.

8 Para Ramón, el respeto a la diversidad de identidades de género engloba, al menos, tres derechos fundamentales: 1) la dignidad humana; 2) el derecho al libre desarrollo de la personalidad; y 3) el derecho al respeto de la vida privada. A este marco jurídico, debemos añadir otros principios y derechos fundamentales, como la no discriminación por razón de identidad o el propio derecho a la identidad. Confróntese, RAMÓN (2017), pp. 20-23.

9 El Comité de los Derechos del Niño en su Observación General № 20 (2016) sobre la efectividad de los derechos del niño durante la adolescencia, se pronuncia con una claridad manifiesta al estipular que "los adolescentes gais, lesbianas, bisexuales, transgénero e intersexuales suelen ser objeto de persecución, lo que incluye maltrato y violencia, estigmatización, discriminación, intimidación, exclusión de la enseñanza y la formación, así como la falta de apoyo familiar y social, y de acceso a la información 
Efectivamente, gran parte de nuestra sociedad continúa anclada en la idea de que la sexualidad, la identidad y la (des)identificación con los roles de género tradicionales son temas tabús, especialmente cuando se refiere al universo de ciudadanos que no han alcanzado todavía la mayoría de edad. Ello hace que bajo el mito de la "inocencia de la infancia y su protección" -que hace más mal que bien-, las personas menores de edad sean directamente desposeídas de su derecho a poder disentir con las expectativas que el mundo adulto céntrico binario proyecta sobre $\mathrm{sí}^{10}$.

Ante un panorama como el descrito, el riesgo de aislamiento, discriminación y acoso-escolar, sanitario, social- que corren las niñas, niños y adolescentes trans* es muy elevado ${ }^{11}$. Entre las consecuencias más extremas de la vulnerabilidad de estas personas - que son las que suelen atraer la atención de los medios de comunicación- están los episodios de violencia física y verbal y el subsiguiente abandono escolar en el que a menudo desembocan ${ }^{12}$. Pero, al mismo tiempo, no hay que perder de vista la identificada como violencia silenciosa que este colectivo de niños, niñas y adolescentes soportan a lo largo de todo su proceso de crecimiento y socialización, una violencia que no es posible cuantificar y que se apoya en estructuras de desigualdad culturalmente muy arraigadas: entre ellas, y sin ánimo de ser exhaustivos, la segregación espacial por sexos y la naturalización de los estereotipos y asignaciones de género que se dan tanto desde la escuela y los centros de salud, como desde otras instituciones

y los servicios sobre salud sexual y reproductiva. En casos extremos, se ven expuestos a agresiones sexuales, violaciones e incluso la muerte". CRC/C/GC/20, de 6 de diciembre de 2016, párrafo 33.

10 Ravetllat (2015), pp. 1-123. Para Missé, en la mayoría de situaciones el miedo y la incomprensión está más presente en los adultos que en los propios niñ@s. Seguramente, prosigue dicho autor, en su pequeño mundo de juegos y diversiones no están teniendo la sensación de estar haciendo algo malo o incorrecto. Pero los adultos, sabedores de las consecuencias que tiene en nuestra sociedad transgredir las normas de género, imaginan que esa situación puede tener graves consecuencias. Confróntese, MISSÉ (2013), pp. 27-28.

11 Para López, no aceptar la identidad de género y la orientación sexual de un adolescente debería considerarse como forma grave de maltrato. Confróntese, LóPEZ (2013), pp. 209-210.

12 En Declaración de 16 de mayo de 2017 emitida por el Comité de los Derechos del Niño y otros mecanismos de derechos humanos regionales y de las Naciones Unidas, en conmemoración del Día Internacional contra la Homofobia, Transfobia y la Biofobia, se constata como los/as niños/as y adolescentes trans y de género diverso son más vulnerables a la violencia en la escuela (acoso) y a la exclusión en la clase, en los juegos, en los baños y en los vestuarios, camino a la escuela y a casa y en la red (ciberacoso). En ese sentido, prosigue la Declaración, un entorno hostil puede, lamentablemente, llevar a estudiantes trans y de género diverso a abandonar la escuela y la familia a una edad temprana. Quedan expuestos a la carencia de hogar, a los mercados laborales informales, a la economía delictiva, a ser objeto del uso de perfiles por la policía y a un ciclo de pobreza, marginación y más discriminación y violencia para el resto de su vida. Disponible en http://www.ohchr.org/SP/NewsEvents/Pages/ DisplayNews.aspx?NewsID=21622\&LangID=S (fecha consulta: 21 de febrero de 2018). 
de socialización (la familia, la iglesia, el mercado laboral, el sistema normativo y los medios de comunicación) $)^{13}$.

Tal circunstancia, y siempre atendiendo al principio del interés superior del niño/a, debiera llevar al legislador chileno a mantener, sin ningún género de dudas, a la niñez y la adolescencia en el Proyecto de Ley de Identidad de Género $^{14}$, ya no por una simple cuestión de justicia social para con los niños y niñas trans*, sino más bien por una exigencia de carácter internacional emanada directamente de los preceptos de la Convención sobre los Derechos del Niño, que no es otra que la de ofrecer a todas y cada una de las personas menores de edad residentes en Chile, plena atención y protección con independencia de su orientación sexual e identidad y expresión de género (artículos $2^{\circ}$ y $8^{\circ}$ de la Convención sobre los Derechos del Niño) ${ }^{15}$.

13 En la Encuesta Nacional de Clima Escolar en Chile 2016, realizada por la Fundación Todo Mejora, se nos muestra cómo el 70,3\% de los/as estudiantes LGBT entrevistados, reportaron sentirse inseguros/ as en la escuela debido a su orientación sexual o identidad de género. Por otro lado, un 59,9\% declaró haber sido acosado verbalmente producto de la forma en que expresa su género, y un $28{ }^{\prime} 6 \%$ fue atacado físicamente por ese mismo motivo. Otro dato digno de ser tomado en consideración es que el $94,8 \%$ de los/as alumnos/as encuestados/as afirmó haber escuchado de sus conpañeros/as comentarios negativos basados en la orientación sexual o la identidad de género, y el 59,9\% lo hizo en boca del personal del centro educativo. Por último, evidenciar que los/as estudiantes que han pasado por niveles más altos de abuso verbal relacionados con su expresión de género son dos veces más propensos de faltar a la escuela durante el último mes (50,7\% vs 27,0\%). Confróntese, Fundación TODo Mejora (2016), p. 15. Por su parte, Echávarri et al. nos recuerdan que Chile duplica la tasa de mortalidad juvenil por suicidio de Latinoamérica y el Caribe, así como constatan que la mayoría de jóvenes que realizan una conducta suicida han vivido situaciones estresantes en los últimos meses, a nivel interpersonal, laboral, académico o financiero. Por el contrario, se observa cómo las relaciones familiares y sociales satisfactorias y de calidad, así como los cuidados parentales suficientemente buenos, constituyen un importante factor protector. Confróntese, ECHÁVARRI (2015), pp. 6-8. Finalmente, cabe destacar que según datos de la Organization for Economic Cooperation and Development (OECD), Chile es el segundo país del mundo en que más ha aumentado la tasa de suicidio adolescente, lo cual es especialmente relevante al considerar que la asociación entre victimización y suicidio es más alta en adolescentes LGTB. Confróntese, OECD (2015), pp. 56-58.

14 Otros ejemplos en el contexto latinoamericano son los que encontramos, por ejemplo, en Argentina, Uruguay o Bolivia. En el primero de los casos, la Ley argentina $N^{\circ} 26.743$, de 23 de mayo de 2012, Ley de Identidad de Género, sí hace referencia expresa a la realidad de las personas menores de edad trans* en sus artículos $5^{\circ}$ y 11 . Por su parte, la Ley uruguaya $\mathrm{N}^{\circ} 18.620$, de 25 de octubre de 2009, de Regulación del Derecho a la Identidad de Género, Cambio de Nombre y Sexo Registral, reconoce en su artículo $1^{\circ}$ este derecho a "toda persona", por tanto se entienden incluidos los niños, niñas y adolescentes. En cambio, la Ley boliviana № 807, de 21 de mayo de 2016, Ley de Identidad de Género, excluye de su ámbito de aplicación y alcance a las personas menores de dieciocho años (artículo 4.1).

15 Para el Comité de los Derechos del Niño (2013): Observación General № 14, de 29 de mayo, sobre el derecho del niño a que su interés superior sea una consideración primordial, CRC/C/GC/14, párrafo 55, la identidad del niño/a abarca características como el sexo, la orientación sexual, el origen nacional, la religión y las creencias, la identidad cultural y la personalidad. El derecho del niño/a a preservar su 
El Estado chileno, tal y como se encargó de recordarnos el propio Comité de los Derechos del Niño en sus recomendaciones finales tras el examen de los Informes periódicos cuarto y quinto, de octubre de $2015^{16}$, está claramente al debe en esta cuestión. En este sentido, el Comité ginebrino expresa su preocupación por la persistencia de actitudes y prácticas discriminatorias con respecto a los niños y niñas homosexuales, bisexuales, transgénero e intersexo, y recomienda al Estado parte redoblar los esfuerzos destinados a combatir las actitudes negativas y eliminar la discriminación de que son víctimas este grupo concreto de personas menores de edad.

En el presente artículo abordaremos, pues, el análisis de la realidad social y el marco jurídico, presente y proyectado, en el que se enmarca la vida de este colectivo de niños, niñas y adolescentes. Para ello, en primer lugar, procederemos a un breve apunte acerca de la cuestión terminológica. Efectivamente, indagar sobre cuáles son las principales diferencias existentes entre las ideas de sexo y género, así como arrojar cierta clarividencia sobre el acervo conceptual utilizado habitualmente, con más o menos fortuna, al tratar sobre estas cuestiones, ocuparán nuestras páginas iniciales. Acto seguido, expondremos minuciosamente el marco jurídico general aplicable a la materia objeto de nuestro estudio, para de este modo estar en predisposición de valorar si la perspectiva de niñez ha sido tomada en consideración o, por el contrario, ha sido una vez más postergada. Finalmente, ahondaremos en la realidad cotidiana de las niñas, niños y adolescentes trans*, presentando cuáles son algunas de sus principales necesidades, e insistiendo en la vital importancia de que se reconozca, desmedicalice y despsiquiatrice su existencia, es decir, que se geste el cambio desde un modelo biomédico, en el que se patologiza a este tipo de individuos, hasta un modelo para la interpretación, el conocimiento y la intervención que ha de ser de carácter biopsicosociocultural.

\section{Cuestión terminológica}

En un contexto como el apuntado, no puede obviarse el decisivo papel que juega el lenguaje en el proceso de construcción de nuestro entorno social. Queda atrás la consideración racionalista de valorarlo como un simple medio de representación o reproducción de la realidad. Por el contrario, la terminología que empleamos -y muy en particular la legal- modela y dirige nuestra

identidad está garantizado por la Convención (artículo $8^{\circ}$ ) y debe ser respetado y tenido en cuenta al evaluar el interés superior del niño/a.

${ }^{16}$ Comité de los Derechos del Niño (2015): Observaciones finales. Examen de los informes periódicos cuarto y quinto presentados por el Estado chileno, octubre de 2015 - Documento CRC/C/CHL/CO/4-5, párrafos 24-25. 
forma de entender y comprender el mundo que nos rodea, y nuestro modo de calificar y denominar a las diversas instituciones se convierte en una forma de acuerdo o pacto social ${ }^{17}$.

Consecuentemente, los regímenes discursivos dominantes operan a través de los giros, las convenciones, las subdivisiones y las categorías que utilizamos para analizar, construir y describir la realidad; a través de ellos, reconocemos lo que es considerado como verdadero o falso, como normal o anormal, como correcto o equivocado. Las definiciones y las clasificaciones se erigen, por ende, en un marco que limita y conforma nuestro modo de pensar y que, de manera más o menos consciente, gobierna nuestros propósitos y acciones. Así, el significado de ciertos conceptos debe ser tratado con precisión para encontrar aquellos resquicios de discriminación que aún sobreviven en nuestro sistema social y jurídico.

\subsection{Sexo y género}

El sexo sería lo biológico y es expresión de la dualidad biológica varón/ mujer, es decir, clasifica a las personas en hombre, mujer y si se quiere intersex, basándose esencialmente en sus características biológicas y anatómicas, mientras que el género sería lo cultural ${ }^{18}$. Así, con la expresión género se quiere significar que la realidad integral del ser humano supera la biología, en el sentido de que, en la conformación y desarrollo de la identidad sexual, poseen,

\footnotetext{
17 Apunta Barudy que el mundo se construye de acuerdo con la manera como es percibido, o en otras palabras, el mundo, tal y como lo observamos, es el mundo de los sistemas observantes en que la propia manera de observar modifica ya lo observado. Confróntese, BARUdY (1998), pp. 29-30.

18 Para Aparisi, el género conduce a una representación psicológico-simbólica, una construcción histórica y antropológico-cultural. Integra, asimismo, roles y pautas de comportamiento, con los condicionamientos sociales que ello conlleva. Confróntese, ApARISI (2015), pp. 37-49. En una línea similar, Solsona entiende que con el término género se establece sobre las personas una clasificación de origen cultural, que ya no se sustenta en la genética o la biología, pero que nos otorga una identidad determinada, una forma de ser, de expresarnos, de actuar y de sentir que reproduce las desigualdades por razón de sexo y discrimina a todo aquel que se atreva a cuestionarlo. Confróntese, Solsona (2016), pp. 20-26. Por otra parte, según el Preámbulo de los Principios de Yogyakarta, marzo de 2007, referentes a la Aplicación de la Legislación Internacional de Derechos Humanos en Relación con la Orientación Sexual y la Identidad de Género, se entiende por identidad de género "a la vivencia interna e individual del género tal como cada persona la siente profundamente, la cual podría corresponder o no con el sexo asignado al momento del nacimiento, incluyendo la vivencia personal del cuerpo (que podría involucrar la modificación de la apariencia o la función corporal a través de medios médicos, quirúrgicos o de otra índole, siempre que la misma sea libremente escogida) y otras expresiones de género, incluyendo la vestimenta, el modo de hablar y los modales". Por último, Puche, Moreno, y Pichardo defienden que el propio concepto de "identidad de género" es problemático, porque naturaliza y esencializa lo que no es sino un constructo social, que termina convirtiéndose en fuente y esencia de lo que el sujeto es (para sí y para los demás). Confróntese, Puche, Moreno y Pichardo (2013), p. 193.
} 
asimismo mucha importancia la educación, la cultura y la libertad. De tal forma que el sexo y el género serían dos dimensiones que confluyen en una misma realidad: la identidad del ser humano. Con esta premisa, el sexo y el género no se consideran como realidades antagónicas, sino como complementarias ${ }^{19}$. Clarificar en este punto, que al emplear la expresión identidad de género hacemos referencia al sentimiento de pertenecer a un determinado género, biológica o psicológicamente ${ }^{20}$. Es inherente al propio sujeto, en otras palabras, es un elemento esencial de su " $\mathrm{yo}^{\prime 21}$. Pues bien, toda persona para alcanzar un nivel pleno de bienestar, necesita que exista una cierta coherencia entre lo que es y lo que siente que es, e incluso lo que los otros piensan que es ${ }^{22}$.

19 LÓPEZ (2016), p. 17.

20 También hay otros términos como "variante de género" (gender variant). Este término enfatiza la idea de ser algo distinto a lo más común, tratándole de otorgar a la cuestión un énfasis positivo. También se utiliza la expresión "personas que no cumplen (o no conforman) los mandatos de género" (gender non-conforming). Son personas que no encajan necesariamente ni en la masculinidad ni en la feminidad como tradicionalmente han venido siendo definidas.

21 Para López, cuando hablamos de identidad nos referimos a la conciencia del YO, que es el núcleo permanente de la identidad. Yo he sido, soy y seré siempre yo, nunca otro, el mismo, más allá de los posibles cambios más o menos importantes. Dicho de otro modo, el YO no cambia en cuanto a tal, no cambia en lo que tiene de esencial, lo que me define como persona. Confróntese, López (2013), p. 210. Desde otra perspectiva, Ventura, y Vaz defienden que el proceso de construcción identitario adquiere dos vertientes: la endógena y la exógena. La primera se refiere al plano individual, es decir, al modo en que el sujeto construye su propia identidad en una tarea de autoidentificación. La exógena, por su parte, se refiere al modo en que la sociedad construye, representa y define una identidad externa -el otro-. Ambos procesos son simultáneos y se modifican el uno al otro. Confróntese, VENTURA Y VAZ (2014), p. 462.

22 De acuerdo con la Orden de la Superintendencia de Educación № 768, de 27 de abril de 2017, relativa a los derechos de las niñas, niños y estudiantes trans en el ámbito de la educación, p. 2, la identidad de género se refiere a la vivencia interna e individual del género tal como cada persona la siente profundamente, la cual podría corresponder o no con el sexo asignado al nacer, incluyendo la vivencia personal del cuerpo. Idéntica definición es la adoptada por la Unidad de Inclusión y Participación Ciudadana del Ministerio de Educación chileno (2017): Orientaciones para la inclusión de las personas lesbianas, gays, bisexuales, trans e intersex en el sistema educativo chileno. Santiago, Ed. Ministerio de Educación, pp. 26 y 44. En Argentina, la Ley № 26.743, de 23 de mayo de 2012, en su artículo $2^{\circ}$, reproduce exactamente la misma idea. En igual medida, el artículo $3^{\circ}$ de la Ley boliviana № 807, de 21 de mayo de 2016. Otras manifestaciones similares del mentado concepto podemos encontrarlas en el Derecho europeo, más concretamente en el ordenamiento jurídico español. Así, la Resolución de 25 de enero de 2017, del Instituto de la Mujer de Castilla la Mancha, por la que se acuerda dar publicidad al Protocolo de Actuaciones dirigido a Menores sobre Identidad y Expresión de Género, se entiende por identidad sexual y/o de género "la vivencia interna o individual del género tal y como cada persona la siente y la auto determina, sin que deba ser definida por terceros, pudiendo corresponder o no con el sexo asignado al momento del nacimiento, y pudiendo involucrar la modificación de la apariencia o la función corporal a través de medios farmacológicos, químicos o de otra índole, siempre que ello sea libremente escogido". Esta misma definición es la recogida en el artículo $1^{\circ}$ de la Ley $N^{\circ}$ 2/2016, de 29 de marzo, de Identidad y Expresión de Género e Igualdad Social 


\subsection{Transexual, transgénero, travesti e intersexual}

Tal y como ya hemos avanzado, en el campo que estamos tratando la cuestión terminológica y conceptual es compleja ${ }^{23}$. No obstante, una de las cuestiones que llama más poderosamente la atención cuando se suscita el tema de las personas trans*, no particularmente en el ámbito de la niñez y la adolescencia, sino en general, es que se suele tratar de forma conjunta a transexuales, travestis, intersex y transgénero, entre otras categorías ${ }^{24}$. Ello, evidentemente, supone un craso error que esconde un alto grado de discriminación, al tratarse de realidades completamente distintas y que, por otra parte, dificulta un abordaje eficiente de todas y cada una de las necesidades propias de cada uno de los mentados colectivos. Por ello, y evitando en la medida de lo posible ofrecer una definición nominal cerrada de cada una de esas realidades, sí consideramos imprescindible, por el valor pedagógico que ello pudiera ostentar, que apuntemos algunas de las características esenciales que identifican a cada uno de esos grupos de individuos ${ }^{25}$.

\footnotetext{
y No Discriminación de la Comunidad de Madrid y en el artículo $4^{\circ}$ de la Ley № 8/2017, de 7 de abril, integral de reconocimiento del derecho a la identidad y a la expresión de género en la Comunidad de Valencia-DOCV № 8019, de 11 de abril de 2017-.

${ }^{23}$ Para Platero, la identidad es una experiencia compleja que engloba cómo nos sentimos, y que puede ir desde si estamos conformando o reafirmando o no, las expectativas sobre nuestro comportamiento, que se basa en qué atribución hacemos a las categorías mujer y hombre. Puede incluir no sentirse dentro de ninguna de estas dos categorías (mujer/hombre) o sentir la identidad de género opuesta a la señalada. También puede implicar tener actitudes y roles sociales determinados, presentarse socialmente de forma ocasional o permanente de un género distinto al asignado, o vivir todo el tiempo en el género elegido. Puede incluir la modificación corporal, o no, a través de hormonas, cirugías mayores o menores. Y puede que se haga a veces o puede que sea un viaje de transición que dura toda la vida. Una persona trans puede tener un aspecto masculino o femenino, puede ser un varón trans o una mujer trans, o puede rechazar incluso ser categorizado dentro de alguna de estas dos opciones. Puede autodenominarse de muchas maneras, ya que no todas las experiencias trans son iguales. Confróntese, Platero (2014a), p. 184.

24 Sin ir más lejos, tenemos a las personas queer (término inglés que puede traducirse como raro). La teoría queer se reapropia de un concepto estigmatizante, para transformarlo en un motivo de posicionamiento político y de orgullo. Así, la diferenciación entre naturaleza (sexo) y cultura (género) entró en crisis a partir de la llegada de esta teoría originada en Estados Unidos a finales de la década de 1980 y principios de 1990. Otra categoría sería la de las Tomboy (expresión inglesa que originariamente significaba chico rudo), que identifica -con esa obsesión que la sociedad actual tiene de etiquetar-a las chicas que visten y se comportan supuestamente de manera masculina.

25 En un sentido similar se pronuncia Gavilán, quien, tras reconocer las dificultades de ofrecer una definición de transexualidad, lo argumenta afirmando que cualquiera de las definiciones que se suelen dar ya lleva implícitos unos prejuicios, unas creencias injustificadas y toda una serie de tópicos y falsos conocimientos que dependen del punto de vista de la persona y del modelo teórico en el que se define. O simplemente acarrea los valores y la perspectiva de las disciplinas desde las que se la intenta definir. Confróntese, GAVILÁN (2016), p. 5.
} 
El travestismo, por ejemplo, no tiene un deseo profundo de cambiar de sexo, sino que se ha instaurado una necesidad psíquica de ponerse ropa del otro sexo, como condición necesaria para alcanzar la excitación sexual. Más aún, en el travesti concuerda la identidad de género con el sexo biológico. Al travestismo se le ha venido considerando una parafilia que supone la activación sexual por medio de objetos y situaciones que no forman parte de las pautas habituales. En suma, el travestismo se refiere a un cambio en la expresión de género (vestimenta, ademanes, comportamiento) sin que realmente exista una identificación interna y esencial con el nuevo género; se suele manifestar como un juego performativo de carácter puntual.

En cambio, el transexual sí que opta, incluso se puede decir que necesita, adoptar los rasgos del otro sexo de forma continua y en algunos casos la hormonación e incluso la reasignación de sexo. Para el Diccionario de la Real Academia de la Lengua, un transexual es la persona "que mediante tratamiento hormonal e intervención quirúrgica adquiere los caracteres sexuales del sexo opuesto" ${ }^{26}$.

La tercera categoría en cuestión es la de las personas intersex. En este caso, no existe conflicto alguno entre la identidad de género y el individuo: cada sujeto tiene un sexo asumido, varón o mujer, que para él no ofrece dudas; no hay un problema psicológico y no tienen en absoluto la percepción de pertenecer a un tercer sexo o de ser andróginos ${ }^{27}$. No obstante, en estos casos, cuando una niña o un niño nacen con características sexuales no claramente definidas, tanto femeninas como masculinas, habrá que optar, atendiendo al principio del interés superior del niño/a, por aquellos procesos, médicos y/o legales, menos drásticos, agresivos e irreversibles para con su persona y desarrollo integral ${ }^{28}$.

\footnotetext{
${ }_{26}$ Para Balza, podemos definir transexual como aquel que se siente del sexo opuesto al que le marca su sexo biológico. La transexualidad se entiende entonces, apunta dicha autora, como efecto de una situación ideológica y tecnológica. Esta situación tecnológica hace referencia a la posibilidad quirúrgica de llevar a cabo operaciones de reasignación de género, con su consiguiente tratamiento hormonal. Y, de otra, la situación ideológica hace mención a la rigidez del sistema sexo/género que mantiene el carácter binario y excluyente del sexo y del género (sólo es posible ser hombre o mujer, macho o hembra) -dimorfismo sexual-. Confróntese, BalzA (2009), pp. 245-248. Por su parte, y aun estando de acuerdo en líneas generales con este concepto de transexualidad, Puche, Moreno y Pichardo añaden que debido a la estrecha ligazón cultural existente entre el sexo anatómico y la identidad de género del sujeto (es decir, el que sea considerado socialmente y se considere a sí mismo como hombre o como mujer), la identidad sexual se entrelaza con la identidad de género hasta el punto de volverse prácticamente indistinguibles. Confróntese, PuChe, Moreno y Pichardo (2013), pp. 191-192.

27 Elósegui (1999), p. 115; Marcuello y Elósegui (1999), pp. 459-477.

${ }^{28}$ El Preámbulo de los Principios de Yogyakarta, marzo de 2007, referentes a la Aplicación de la Legislación Internacional de Derechos Humanos en Relación con la Orientación Sexual y la Identidad de Género expresa, refiriéndose a este tipo de cuestiones, que "una consideración primordial en todas las acciones concernientes a niñas y niños será su interés superior, y que una niña o niño que esté en
} 
En efecto, entendemos que no es necesario precipitarse asignando e inscribiendo un sexo desde el mismo instante del nacimiento, incurriendo de este modo en un grave peligro de arbitrariedad. Debe garantizarse la integridad corporal de las personas menores de edad intersexuales, salvo que haya una motivación médica que así lo justifique, hasta que alcancen el nivel de madurez suficiente para definir por sí mismos su identidad sentida, ofreciéndoseles, además, plena protección de su intimidad y dignidad frente a prácticas de exposición y análisis de carácter abusivo ${ }^{29}$. La protección de las personas intersexuales exige el reconocimiento de la diversidad de los cuerpos humanos y la erradicación del prejuicio según el cual existe un único y dicotómico patrón normativo de corrección corporal, que lleva a que niñas y niños intersexuales sean intervenidos quirúrgicamente a edades muy tempranas para asimilarlos lo antes posible a la pretendida "normalidad" de ser hombre o mujer, sin saber cuál es realmente su verdadera identidad, corriendo el riesgo de cometer graves errores que vengan a condicionar la vida del sujeto ${ }^{30}$.

Por último, hay que hacer referencia al denominado transgénero, se trata de quien rechaza la categorización o encasillamiento en uno u otro sexo o género. Para sustentar esta teoría, hay que deconstruir el concepto de identidad masculina o femenina. En resumen, desde esta perspectiva se contempla el género como algo en constante proceso de transformación, donde no existe la obligación de alcanzar una meta específica. El sujeto transgenérico va a reivindicar una nueva corporalidad y una nueva subjetividad, que se muestra transgresora con las categorías sexuales establecidas, al ir más allá de los dos géneros/sexos que la ideología social y cultural reconoce como necesarios ${ }^{31}$. Por ejemplo, la

condiciones de formarse un juicio propio tiene el derecho a expresar su opinión libremente en todos los asuntos que le afectan, teniéndose debidamente en cuenta las opiniones de la niña o el niño, en función de su edad y madurez".

29 López (2012), p. 348. Aun estando de acuerdo con lo apuntado, López Guzmán entiende que es muy probable que las niñas y niños intersexo presenten problemas relacionales, ya que en el momento de reconocer su cuerpo evidencian ciertas diferencias con el resto de sus compañeras/os. Confróntese, LÓPEZ (2016), p. 47.

30 Este mismo criterio es el mantenido por la Sociedad de Intersexuales de Norteamérica (Intersex Society of North America), www.isna.org (fecha consulta: 21 de febrero de 2018). También Amnistía Internacional se ha pronunciado en este sentido. AmNeSTy INTERNATIONAL (2017), p. 59. Por último, la Circular № 18, de 22 de diciembre de 2015, del Ministerio de Salud de Chile, instruye expresamente a los centros de salud para que "detengan los tratamientos innecesarios de normalización de niños y niñas intersex, incluyendo cirugías genitales irreversibles, hasta que tengan edad suficiente para decidir sobre sus cuerpos".

31 Balza (2009), pp. 247 y 251-254. Para Puche, Moreno y Pichardo, en el contexto euroamericano se denomina persona transgénero a quien experimenta una inadecuación entre sexo anatómico e identidad de género, pero resuelven su situación actuando principalmente sobre el rol social de género (vestimenta, nombre, hábitos sociales, actitudes) y no tanto sobre el cuerpo; en especial, evitan 
persona transgénero puede decidir tomar hormonas y, en cambio, no operarse $\mathrm{o}$, por el contrario, puede llegar a operarse y no hormonarse ${ }^{32}$. Cualquiera de las combinaciones es plenamente válida, a la par que respetable.

\section{Evolución del marco normativo y jurisprudencial internacional}

Un primer hito se alcanzó con la promulgación de los principios de Yogyakarta relativos a la aplicación dela Legislación Internacional de Derechos Humanos en Relación con la Orientación Sexual e Identidad de Género, presentados ante la Asamblea de Derechos Humanos de las Naciones Unidas, en marzo de $2007^{33}$. Entre otras muchas cuestiones, este texto mantiene en su principio $\mathrm{N}^{\circ} 17$, relativo a la protección contra abusos médicos, un claro enfoque de derechos humanos, al afirmar que "la orientación sexual y la identidad de género de una persona no constituyen, en sí mismas, trastornos de la salud y no deben ser sometidas a tratamiento o atención médicas, ni suprimidas".

Posteriormente, en el año 2011, se adoptó la Resolución 17/19 del Consejo de Derechos Humanos de las Naciones Unidas bajo la rúbrica "Derechos humanos, orientación sexual e identidad de género" ${ }^{\prime 34}$, que representa la primera resolución de este estilo adoptada por este organismo internacional. Este documento abrió el camino al primer informe oficial de las Naciones Unidas sobre la cuestión, elaborado por la Oficina del Alto Comisionado de las Naciones Unidas para los Derechos Humanos, denominado “Leyes y prácticas discriminatorias y

la cirugía de reasignación genital y a veces también la hormonación. Confróntese PUCHE, MORENO Y PiCHARDO (2013), p. 192.

32 De forma más amplia e inclusiva, se emplea en determinados ámbitos la fórmula "persona trans" o "trans" sin más, que pretende sobrevolar las precisiones corporales y quirúrgicas y poner el acento en el tránsito, en la transformación, la interpelación o la transgresión de los códigos de sexo/género normativos, al margen de los medios por los que se lleve a cabo (incluyendo a personas transexuales, transgénero y otras).

33 Un distinguido grupo de especialistas en derechos humanos redactó, desarrolló, discutió y refinó estos principios. Luego de reunirse en la Universidad de Gadjah Mada en Yogyakarta, Indonesia, del 6 al 9 de noviembre de 2006, 29 reconocidos y reconocidas especialistas procedentes de veinticinco países, de diversas disciplinas y con experiencia relevante en el ámbito del derecho internacional de los derechos humanos, adoptaron en forma unánime los Principios de Yogyakarta sobre la Aplicación de la Legislación Internacional de Derechos Humanos en Relación con la Orientación Sexual y la Identidad de Género. Cada principio se acompaña de recomendaciones detalladas dirigidas a los Estados. No obstante, los Principios también incluyen recomendaciones adicionales dirigidas a otros actores, incluyendo al sistema de derechos humanos, los medios de comunicación, las organizaciones no gubernamentales y las agencias financiadoras.

${ }^{34} \mathrm{~A} / \mathrm{HCR} / \mathrm{RES} / 17 / 19$, de 11 de julio de 2011. El documento completo puede consultarse en http:// arc-international.net/wp-content/uploads/2011/09/HRC-Res-17-19.pdf (fecha consulta: 21 de febrero de 2018). 
actos de violencia cometidos contra personas por su orientación sexual e identidad de género"35, y más recientemente (2013) al documento "Nacidos libres e iguales: orientación sexual e identidad de género en las normas internacionales de derechos humanos" ${ }^{\prime 36}$.

En esta misma línea, la Asamblea General de la Organización de Estados Americanos-OEA-, solicitó, en el año 2009, a la Comisión Interamericana de Derechos Humanos - $\mathrm{CIDH}$ - que incorporara dentro de sus preocupaciones las temáticas relacionadas con la vulneración de los derechos de las personas LGBTI, creándose de este modo, en el año 2014, la Relatoría sobre Derechos de las Personas LGBTI ${ }^{37}$.

Siguiendo ese mismo criterio evolutivo, la Asamblea General de la OEA aprobó en el año 2013 la Convención Interamericana contra Toda Forma de Discriminación e Intolerancia. En este instrumentoexiste una clara referencia a la orientación sexual, identidad y expresión de género como ámbitos libres de discriminación.

Recientemente, el 30 de junio de 2016, el Consejo de Derechos Humanos de la ONU ha creado la Relatoría sobre la materia, nombrando a un experto independiente encargado de monitorear la violencia y la discriminación por motivos de orientación sexual o identidad de género. Este relator tiene como misión dialogar con los Estados parte; organismos internacionales pertinentes; organizaciones de la sociedad civil; instituciones nacionales de derechos humanos y foros académicos, para promover la aplicación de medidas que contribuyan a la protección de todas las personas que sean víctimas de la violencia y la discriminación por motivos de orientación sexual o identidad de género ${ }^{38}$.

Asimismo, y haciendo ahora referencia a la jurisprudencia emanada de las cortes internacionales de derechos humanos, la cuestión parece estar mucho más desarrollada en el contexto del Tribunal Europeo de los Derechos Humanos -en adelante TEDH- y en menor medida en el seno de la Corte Interamericana de Derechos Humanos -en adelante CIDH-.

\footnotetext{
35 A/HCR/19/41, de 17 de noviembre de 2011. El documento completo puede consultarse en http:// www.ohchr.org/documents/issues/discrimination/a.hrc.19.41_english.pdf (fecha consulta: 21 de febrero de 2018).

36 Documento en: http://www.ohchr.org/Documents/Publications/BornFreeAndEqualLowRes_SP. pdf (fecha consulta: 21 de febrero de 2018).

37 Para mayor información consultar la página web de la Relatoría sobre los Derechos de las Personas LGBTI de la Organización de los Estados Americanos - OEA - http://www.oas.org/es/cidh/lgtbi/ (fecha consulta: 21 de febrero de 2018).

${ }^{38} \mathrm{~A} / \mathrm{HRC} / 32 / \mathrm{L} .2 / \operatorname{Rev} .1$, de 28 de junio de 2016. El documento completo puede consultarse en https:// documents-dds-ny.un.org/doc/UNDOC/LTD/G16/135/03/PDF/G1613503.pdf?OpenElement (fecha consulta: 21 de febrero de 2018).
} 
En este sentido, si bien es cierto que tradicionalmente se identificó, e incluso limitó, la cuestión legal referente a las personas trans* con la autorización o no a las intervenciones quirúrgicas para la reasignación genital, la realidad que abarca esta materia es, sin embargo, mucho más amplia y compleja. Por ejemplo, el TEDH tuvo que pronunciarse en el caso Rees vs. Reino Unido sentencia de 17 de octubre de 1986- acerca de la denegación a un súbdito británico, al que previamente se le había admitido un cambio de sexo, nombre e incluso de pasaporte, de su tratamiento de "Sr."; o en el caso Cossey vs. Reino Unido -sentencia de 27 de septiembre de 1990- en el que un hombre británico hizo su tránsito legal al sexo femenino y después solicitó contraer nupcias con un varón italiano, cuestión ésta que le fue denegada ${ }^{39}$; o el emblemático caso Christine Goodwin vs. Reino Unido -sentencia de 11 de julio de 2002-, que supuso un antes y un después en la línea jurisprudencial seguida por el Tribunal de Estrasburgo en estas cuestiones ${ }^{40}$.

Efectivamente, en los primeros casos presentados por demandantes trans* que se consideraban víctimas de violaciones del Convenio Europeo para la Protección de los Derechos Humanos y de las Libertades Fundamentales -en adelante $\mathrm{CEDH}-$, al emitir sus decisiones, el TEDH siempre había sido muy condescendiente con las políticas y las leyes nacionales en relación con este asunto. Para ello aludía a que la dispar legislación de los Estados en la materia demostraba la falta de unidad de criterio entre ellos y, en consecuencia, el amplio margen de apreciación estatal que quedaba y que el TEDH les debía reconocer ${ }^{41}$.

Pues bien, en el caso Christine Goodwin vs. Reino Unido, el TEDH entiende que el Estado británico incumplió el CEDH al permitir a una persona someterse a una operación de reasignación genital, pero acto seguido impedirle cambiar en el Registro Civil los datos relativos a su sexo y, además, negarle la posibilidad

\footnotetext{
39 El TEDH consideró que no había vulneración del artículo 12 del CEDH -que recoge el derecho a contraer matrimonio- pues estimó que la protección del matrimonio tradicional es un valor tan importante para la sociedad que justificaría que el Estado siga empleando el criterio biológico a la hora de decidir quiénes pueden ser contrayentes. Por ello, la Corte de Estrasburgo estimó que no debía cambiar su posición respecto a su jurisprudencia anterior.

40 Sanz-Caballero se encarga de realizar un estudio pormenorizado de este cambio de criterio jurisprudencial seguido por el TEDH. Confróntese Sanz-Caballero (2014), pp. 831-868.

${ }^{41}$ No obstante, antes de los emblemáticos casos Goodwin vs. ReinoUnido e I. vs. ReinoUnido, ambas sentencias de 11 de julio de 2002, en concreto en B. vs. Francia, sentencia de 25 de marzo de 1992, X.Y. y Z. vs. Reino Unido, de 22 de abril de 1997, y Sheffield y Horsham vs. Reino Unido, de 30 de julio de 1998, el TEDH pareció dar ya sus primeros pasos para alinearse con las pretensiones de las personas transexuales. En estas tres resoluciones de los años noventa, el TEDH estableció, si bien entre líneas, que simpatizaba con la difícil situación personal, familiar y social del colectivo de personas transexuales, si bien, aunque quisiera, no siempre podía responder afirmativamente a sus pretensiones porque no había un consenso europeo sobre la cuestión.
} 
de contraer matrimonio con una persona del mismo sexo a aquel con el que el transexual nació. La opinión del TEDH en este caso fue que la negativa del Estado a proceder al cambio de datos oficiales supuso, por un lado, una intromisión desproporcionada en el disfrute de las personas transexuales a su derecho a la vida privada -artículo $8^{\circ} \mathrm{CEDH}-$; y, de otro, que el Estado prohibiera al transexual casarse con persona de su mismo sexo cromosómico pero distinto sexo aparente suponía, en definitiva, negarle sin más el derecho a contraer nupcias protegido por el artículo 12 del propio $\mathrm{CEDH}^{42}$.

Posteriormente, y en la senda de ese proceso de reconocimiento de los derechos de las personas trans*, el TEDH, primero en sentencia de 12 de septiembre de 2003, caso Van Kück vs. Alemania ${ }^{43}$, después en el caso H. vs. Finlandia, en sentencia de 13 de noviembre de $2012^{44}$, y más recientemente en sentencia

42 Algo similar sucedió en el caso I. vs. Reino Unido, sentencia del TEDH de 11 de julio de 2002, en que una nacional británica, transexual femenina operada, demandó al Estado británico por vulneración del respeto a la vida privada -artículo $8^{\circ}$ del $\mathrm{CEDH}$ - y al derecho a casarse y fundar una familia -artículo 12 del CEDH-. Concretamente, el Estado británico se enfrentó a la demanda de una persona transexual operada de hombre a mujer que trabajó un tiempo como enfermera del ejército y que, cuando tuvo la oportunidad de que éste le empleara de forma definitiva, tuvo que renunciar al serle solicitado el certificado de nacimiento, en el que seguía figurando como de sexo masculino. Además, en todos sus trámites con la Administración -la solicitud de un préstamo, de una pensión de discapacidad y de un nuevo trabajo, entre otros- se le exigía un certificado de nacimiento que apoyara su solicitud. Por si ello fuera poco, vivía con un hombre y quería contraer matrimonio con él, pero tampoco le era posible, pues continuaba figurando como varón en el Registro Civil. Finalmente, el Reino Unido fue condenado.

43 Este caso se originó en la demanda de una persona que descubrió su transexualidad de modo tardío, puesto que nunca se comportó o se vistió como alguien del otro género, sino que se casó con alguien de su sexo opuesto, intentó tener hijos y sólo cuando se diagnosticó su esterilidad, se empezó a plantear una cirugía de reasignación genital. Por esta razón, una aseguradora alemana se negaba a resarcirle el tratamiento médico y quirúrgico, siendo favorable tan solo al tratamiento psicológico del sujeto. Sin embargo, el TEDH entendió que obligar a la persona transexual a demostrar la necesidad médica de su tratamiento, incluyendo la cirugía irreversible, no era razonable. También mantuvo que, teniendo en cuenta las numerosas y dolorosísimas intervenciones médicas que supone una cirugía de reasignación genital, no se puede sugerir que haya algo arbitrario o caprichoso en la decisión de una persona de cambiar de sexo.

44 En este asunto, una persona nacida de sexo masculino que se casó y tuvo un hijo, es diagnosticada posteriormente como transexual y sigue todos los tratamientos médicos necesarios para adaptar su cuerpo al sexo que siente como propio (el femenino). Completado el proceso, lo único que pide la legislación finlandesa para proceder a cambiar su nombre y sexo en el Registro es, o bien que la persona no esté casada, o bien que su cónyuge consienta transformar su matrimonio -contraído legalmente- en una unión civil homosexual, contemplada también en la legislación finesa. La esposa se niega a ello y sólo desea mantener su matrimonio. La demandante, por su parte, reprocha al Estado que quiera convertir a su esposa en una lesbiana y teme dejar de figurar como "padre" del hijo común, puesto que un niño no puede tener dos madres. El TEDH en su resolución al caso enfatiza que el Estado tiene la obligación positiva de asegurar el respeto de la vida privada y familiar, incluido el respeto a la dignidad humana y a la calidad de vida de las personas. También reconoce que algunos Estados europeos han extendido el derecho al matrimonio a las personas homosexuales, pero que esto sólo refleja su propia visión 
de 10 de marzo de 2015, caso Y.Y. vs. Turquía, considera abiertamente, sin ningún tipo de reparos, que elementos como la identidad o expresión de género, nombre, orientación sexual y vida sexual caen dentro de la esfera de la protección de la vida privada del artículo $8^{\circ}$ del CEDH. Asimismo, la Corte de Estrasburgo entiende que el derecho al desarrollo integral de la personalidad de un sujeto trans* debe ser garantizado al amparo de los principios dimanantes del propio $\mathrm{CEDH}$.

Finalmente, la sentencia del TEDH de 6 de abril de 2017, A.P. , Garçon y Nicot vs. Francia ${ }^{45}$, condena al Estado francés por vulnerar el derecho a la identidad de género de las personas trans*. En su resolución, la Corte de Estrasburgo apunta que el hecho de condicionar el reconocimiento de la identidad sexual de las personas transgénero a la realización de una operación o a un tratamiento de esterilización al cual éstas no desean someterse, supone condicionar el pleno ejercicio del derecho al respeto de la vida privada (artículo $8^{\circ} \mathrm{CEDH}$ ), así como una renuncia al ejercicio del derecho al respeto de la integridad física ${ }^{46}$.

sobre el rol del matrimonio en la sociedad. Sin embargo, entiende que a pesar de que la legislación finesa no admita matrimonios de personas del mismo sexo -en este caso femenino- sí que admite un partenariado o unión civil homosexual al que la demandante y su cónyuge -que hasta su conversión sexual era su esposa- tendrían acceso en cualquier momento si deciden disolver su vínculo conyugal, por ende, concluye entendiendo que no hay vulneración del artículo 12 del CEDH.

45 El caso se refiere a tres personas transgénero de nacionalidad francesa que querían cambiar la referencia de su sexo y sus nombres en su certificado de nacimiento y se encontraron con la negativa de las autoridades del Estado francés. El argumento utilizado por las mentadas autoridades francesas fue que, para justificar dicha solicitud, debía probarse la realidad del síndrome transexual -disforia de género- que sufrían, así como la irreversibilidad de la transformación de su apariencia. Esta decisión se fundamentaba en dos sentencias que el Tribunal de Casación francés dictó (el 7 de junio de 2012 y el 13 de febrero de 2013) en que se establecía el principio de que "para justificar una solicitud de rectificación de la designación del sexo contenida en un nacimiento, la persona deberá establecer, en relación con lo que es comúnmente aceptado por la comunidad científica, la realidad del síndrome transexual y la irreversibilidad de la transformación de su apariencia. Por lo tanto, dos condiciones se plantean: el diagnóstico de transexualismo y la irreversibilidad de la transformación de la apariencia física. Así, si bien la ley no requiere cirugía, sí se pide, en cambio, un tratamiento médico irreversible que implica la esterilización".

46 Cierto es que en Francia, tras la aprobación de la Ley de modernización de la justicia del siglo XXI, de 16 de octubre de 2016, se introdujeron en el Código Civil ciertos cambios relativos a la cuestión del género. Así, en la actualidad, el articulado reconoce a adultos y menores emancipados el derecho a solicitar en procedimiento ante el Tribunal Supremo el cambio de sexo registral. Entre los medios de prueba que enumera se encuentran: 1) que se presente públicamente como perteneciente al género reivindicado; 2) que su entorno familiar, de amistades y profesional le reconozcan con ese género; y 3) que haya obtenido el cambio de nombre para que coincida con el género reclamado. Por último, el nuevo articulado también dispone que el hecho de no haber sido sometido a un tratamiento médico, la cirugía o la esterilización, no puede motivar la denegación de la solicitud. 
En el ámbito regional americano, por su parte, debemos citar la sentencia Atala-Riffo y Niñas vs. Chile, de 24 de febrero de 2012. Este fallo condenó al Estado de Chile por la decisión de la Corte Suprema, mediante la cual arrebató el cuidado y la custodia de sus tres hijas a la jueza Karen Atala en razón de su orientación sexual. En su sentencia final, la Corte Interamericana de Derechos Humanos estableció que la orientación sexual y la identidad de género son categorías protegidas por medio del artículo 1.1 de la Convención Americana. En este sentido, toda discriminación basada en ellas constituye una vulneración del derecho internacional, sentando un extraordinario precedente en materia de los derechos de las personas $\mathrm{LGBT}^{47}$.

En idéntico sentido se pronunció la $\mathrm{CIDH}$ en la sentencia Duque vs. Colombia, de 26 de febrero de 2016, al declarar que la orientación sexual y la identidad de género de las personas son categorías protegidas por el artículo 1.1 de la Convención Americana. En consecuencia, ninguna norma, decisión o práctica de derecho interno, sea por parte de autoridades estatales o por particulares, pueden disminuir o restringir, de modo alguno, los derechos de un sujeto a partir de su orientación sexual, identidad o expresión de género ${ }^{48}$.

\section{Identidad de género de las niñas, niños y adolescentes a la luz de la Convención sobre los Derechos del Niño: modelo, titularidad y ejercicio}

Referenciado el contexto terminológico y el marco normativo y jurisprudencial internacional general relativo al reconocimiento de los derechos humanos de las personas trans*, ahondamos, acto seguido, en las particularidades que se suscitan cuando el sujeto objeto de nuestra atención no ha alcanzado todavía la mayoría de edad.

\subsection{De un modelo patologizante a la libre determinación del género}

La infancia y la adolescencia trans* han sido patologizadas durante décadas. Así, el abordaje tradicional de las cuestiones relativas a las niñas, niños y adolescentes trans* se ha venido realizando desde un modelo terapéutico y patologizante. De acuerdo con este enfoque, se consideraba que la persona menor de edad, y su familia o entorno, debían ser tratadas por un profesional de la salud mental. Con ello, se prescribía al niño o niña un tratamiento reparativo

47 Corte Interamericana de Derechos Humanos, caso Atala Riffo y Niñas vs. Chile, sentencia de 24 de febrero de 2012, párrafo 91.

48 Corte Interamericana de Derechos Humanos, caso Duque vs. Colombia, sentencia de 26 de febrero de 2016, párrafo104. El caso de fondo versa sobre la supuesta responsabilidad internacional de Colombia por la alegada exclusión del señor Duque de la posibilidad de obtener una pensión de sobrevivencia tras la muerte de su pareja, supuestamente con base en que se trataba de una pareja del mismo sexo. 
que debía llevarlo, en la medida de lo posible, a cambiar su identidad disidente para ajustarse al sexo asignado en el momento del nacimiento ${ }^{49}$.

Con posterioridad, y siguiendo en gran medida las clasificaciones internacionales de trastornos mentales contenidas tanto en el Diagnostic and Statistical Manual of Mental Dissorders (DSM) de la Asociación Norteamericana de Psiquiatría (APA) ${ }^{50}$, como de la International Classification of Diseases (ICD) de la Organización Mundial de la Salud $(\mathrm{OMS})^{51}$, -que si bien continúan considerando la transexualidad como un trastorno de la identidado, para ser más exactos, como una situación de disforia de género ${ }^{52}-$, se rechaza ya la idea de tratar de convencer al sujeto menor de edad para que renuncie a su identidad trans*, como sucedía antaño, y, por el contrario, si se le diagnosticara disforia de género, tal circunstancia pasa a ser contemplada como causa justificativa a la hora determinar la viabilidad o no de un cambio registral, la posibilidad de administrar bloqueadores hormonales o incluso de obtener la autorización para someterse a una intervención quirúrgica de reasignación genital ${ }^{53}$. Esta visión

49 El propio Comité de los Derechos del Niño en su Observación General № 20 (2016) sobre la efectividad de los derechos del niño durante la adolescencia, tras reconocer a los adolescentes su derecho a la libertad de expresión y a que se respete su integridad física y psicológica, su identidad de género y su automomía emergente, condena la imposición de tratamientos mediante los que se pretende cambiar la orientación sexual de una persona (el Comité ginebrino parece olvidar aquí condenar también la aplicación de esas prácticas con respecto a la identidad y expresión de género, pero del contexto parece poder extraerse), y que los adolescentes intersexuales sean sometidos a intervenciones quirúrgicas o tratamientos forzados. CRC/C/GC/20, de 6 de diciembre de 2016, párrafo 34). Mucho más claro y contundente se muestra el Comité de los Derechos del Niño en la Declaración de 16 de mayo de 2017, emitida junto con otros mecanismos de derechos humanos regionales y de las Naciones Unidas, en conmemoración del Día Internacional contra la Homofobia, Transfobia y la Biofobia, en el que se realiza un Ilamamiento a los Estados para que despenalicen y despatologicen las identidades trans y de género diversas, en especial de las personas jóvenes trans, para que prohíban las "terapias de conversión" y para que se abstengan de adoptar nuevas leyes penalizadoras y clasificaciones médicas patologizadoras, incluyendo en el contexto de la próxima revisión de la Clasificación Internacional de Enfermedades. Disponible en http://www.ohchr.org/SP/NewsEvents/Pages/DisplayNews. aspx? NewsID=21622\&LangID=S (fecha consulta: 22 de febrero de 2018).

50 La edición vigente es la quinta, conocida como DSM-5, que fue publicada el 18 de mayo de 2013.

51 Actualmente está en vigor la décima edición, conocida como ICD-10 (CIE-10, utilizando las siglas españolas que equivalen a Clasificación Internacional de Enfermedades). Durante el transcurso del año 2018 está prevista su sustitución por la CIE-11.

52 La identidad de género en la infancia y la adolescencia ya se consideró en las primeras clasificaciones internacionales. Por ejemplo, en el DSM-III (1980) se le denominó trastorno de identidad de género en la infancia, así se siguió manteniendo en el DSM-IV (1994), y en la última versión DSM-V (2013), se ha sustituido el término trastorno de identidad de género por el de disforia de género, es decir, la angustia que sufre la persona que no está identificada con su sexo masculino o femenino.

53 López realiza un estudio pormenorizado de la evolución del diagnóstico del transexualismo. Confróntese, LóPEz (2016) pp. 63-67. 
se traduce en la práctica en que la gran mayoría de procedimientos legales que toman en consideración a niños y niñas trans* deben iniciarse con un informe diagnóstico elaborado por un experto en salud mental, lo que supone no abandonar definitivamente una lectura medicalizada y patologizante de la realidad trans*. En definitiva, hemos pasado del paradigma de la perversión, de pensar que esas conductas no son normales, al paradigma de la enfermedad, es decir, que no es que no sean normales, sino que son un trastorno mental.

Durante la última década, y en respuesta a ese modelo psicopatológico, desde los movimientos sociales y ciertos sectores profesionales empieza a emerger una corriente de pensamiento ${ }^{54}$, a la cual nos adscribimos, que entiende que no hay nada negativo, ni extraño en la decisión de una persona menor de edad que decida transitar hacia una identidad de género distinta a la establecida por los estereotipos binarios o dicotómicos imperantes en nuestro modelo social ${ }^{55}$. Desde esta perspectiva es necesario entender la experiencia trans* no como una patología, un desorden identitario o un problema, sino como un conjunto de construcciones y elecciones de carácter personalísimo, de trayectorias heterogéneas, fluidas y cambiantes, que debieran ser legitimadas por la ley. Se impulsa así, el pasaje de un modelo médico a otro fundamentado en los derechos humanos ${ }^{56}$, en el que los/las profesionales de la salud pasan a asumir un rol de acompañamiento, pero dejan de ostentar la facultad de determinar las formas de entender y vivir las identidades y/o expresiones de género, las

\footnotetext{
54 En este sentido, Gavilán nos recuerda que desde el año 2009 hay un movimiento poderoso a nivel internacional denominado STP, que responde al acrónimo de Stop Trans Pathologization, que reúne a 397 grupos, organizaciones y redes procedentes de Asia, América Latina, África, Europa, Norteamérica y Oceanía, cuyo objetivo principal es la retirada de la clasificación de los procesos de tránsito entre los géneros como trastorno mental de los manuales diagnósticos (DSM de la American PsychiatricAssociation y CIE de la Organización Mundial de la Salud), el acceso a una atención sanitaria trans-específica públicamente cubierta, el cambio de modelo de atención sanitaria trans-específica, desde un modelo de evaluación hacia un enfoque de consentimiento informado, el reconocimiento legal del género sin requisitos médicos, la despatologización de la diversidad de género en la infancia, así como la protección contra la transfobia. Confróntese, GAVILÁN (2016)' p. 8.

55 Ese mismo cambio de paradigma se aprecia en la conducta de las propias familias de los niños y niñas trans*: antes los progenitores acudían a la consulta de un profesional de la psicología o la psiquiatría para tratar de resolver el problema del hijo/a, para que se "cure" y, últimamente, se acercan más a esos mismos profesionales para buscar y adquirir herramientas, información y saberes para poder comprender, atender y acompañar a ese hijo/a, para respetarlo y aceptarlo tal cual es.

56 Tal y como señala Lobera, es importante señalar lo relevante que resulta que el reconocimiento de derechos sea complementado por una teoría de la autonomía, que haga posible el ejercicio individual de aquéllos, pues conceder titularidad sin autonomía de ejercicio, nos vuelve a situar en el mismo punto de partida en que nos encontrábamos cuando los derechos no les eran reconocidos a las niñas, niños y adolescentes. Confróntese, LOBERA (2009) pp. 11-55.
} 
orientaciones y/o prácticas sexuales y las transformaciones corporales, que en su caso, puedan llevarse a cabo ${ }^{57}$.

Nadie debiera precisar, a priori, de ningún psicólogo ni psiquiatra que lo diagnostique o evalúe con respecto al género sentido. Las normas sociales de ordenación del sexo y el género deberían ser abiertas y flexibles para permitir que todas las personas, con independencia de su edad, pudieran reconocer su identidad sin problema alguno y que, en caso de error o divergencia, pudieran cambiar su identidad de la forma más sencilla y natural posible. En suma, evidenciar que las niñas y los niños trans* no presentan ningún problema médico, psicológico o psiquiátrico. Por el contrario, los problemas que se les pudieran presentar guardan relación directa con la sociedad que no los admite y los excluye, los segrega y los estigmatiza ${ }^{58}$.

Pues bien, partiendo de esas premisas, de ese intento de despatologizar la realidad de la infancia y la adolescencia trans*, procedemos seguidamente al estudio de la génesis, configuración y ulterior desarrollo del derecho a la identidad en el seno de la Convención sobre los Derechos del Niño -en adelante $\mathrm{CDN}-$, para con ello obtener mayor claridad acerca del verdadero significado y alcance que este tratado internacional ha conferido al mentado derecho de la personalidad.

\subsection{El derecho a la identidad (de género) en la Convención sobre los Derechos del Niño}

En la propuesta inicial de CDN presentada por Polonia en la 34 Sesión de la Comisión de Derechos Humanos de las Naciones Unidas -marzo de 1978-, de los 19 artículos que la integraban, no había ninguno referido explícitamente al derecho a la identidad. Sí, no obstante, el artículo $2^{\circ}$ mencionaba la obligación asumida por los Estados parte de garantizar una especial protección a la niñez, que se concretaba en la necesidad de adoptar todas las medidas necesarias para asegurar su desarrollo físico, mental, moral, espiritual y social de manera saludable y en condiciones de libertad y dignidad.

La iniciativa de incorporar un precepto específico relativo al derecho a la identidad vino de la mano de la República Argentina en el año $1985^{59}$, y detrás

\footnotetext{
57 Señalan Generelo, Pichardo y Galofré que la adolescencia LGTB atraviesa por diversos procesos como: 1) buscar un nombre para lo que sienten, 2) tener iniciativa para encontrar iguales, 3) aceptar la diferencia, y 4) poder tomar decisiones alrededor de revelar (o no) la identidad. Estas fases, finalizan los mentados autores, ni son consecutivas, ni afectan a todos los individuos por igual. Confróntese, Generelo, Pichardo y Galofré (2008),pp. 15. De esta misma opinión es Arjona (2016),pp. 70-73.

58 SWANn y Herbert (2009), pp. 38-52.

59 La versión original presentada por Argentina se pronunciaba del siguiente tenor literal: "The child has the inalienable right to retain his true and genuine personal, legal and family identity. In the event
} 
de su propuesta se escondía la preocupación de esta delegación andina por los cambios de identidad de recién nacidos acaecidos en su territorio durante el período de la dictadura militar -esencialmente la adulteración de documentos públicos y la sustracción de identidades-. Esta propuesta contó con la oposición expresa de las delegaciones de Noruega, Holanda, Austria, Estados Unidos y Canadá, partidarias todas ellas de la no necesidad de inclusión de una disposición al estilo de la apuntada, por considerar que el derecho a la identidad ya se encontraba consagrado en otros artículos del Proyecto de Convención. Secundaron, en cambio, la idea argentina tanto Polonia como Brasil.

Finalmente, y a sugerencia de la delegación brasileña, el open-ended Working Group encargado de los trabajos de elaboración del texto de la $C D N^{60}$, decidió crear un grupo informal integrado por los representantes de Argentina, Holanda, Noruega y Polonia -con la asistencia técnica de la International Commission of Jurist- para que tratara y solventara la cuestión objeto de la controversia. Los trabajos se extendieron durante un período de doce meses -año 1986- y tras arduas discusiones, en las que en ningún momento, por razones obvias de la época, se vinculó identidad y género, se llegó a un acuerdo unánime para: en primer término, incorporar a la CDN un precepto alusivo al derecho a la identidad; y, en segundo lugar, proveer al Working Group de una propuesta de redacción final ${ }^{61}$, iniciativa ésta que a la postre, y tras unas pequeñas modificaciones, se convirtió en el actual artículo $8^{\circ} \mathrm{CDN}$.

Esa falta de sintonía inicial que presentó el artículo $8^{\circ} \mathrm{CDN}$ con una interpretación amplia y omnicomprensiva del derecho a la identidad, que incluyera, entre otras, la acepción relativa a la identidad de género, se continuó manteniendo, una vez ya aprobada la CDN, durante la época de los años noventa. Así, en el documento elaborado por el Comité de los Derechos del Niño en el que se recogen las orientaciones generales respecto de la forma y el contenido de los informes que han de presentar los Estados Partes con arreglo al apartado b) del párrafo 1 del artículo 44 de la CDN, de 20 de noviembre de 199662,

that a child has been fraudulently derpived of some or all of the elements of his identity, the State must give him special protection and assistance with a view to re-establishing his true and genuine identity as soon as possible. In particular, this obligation of the State includes restoring the child to his bloodrelations to be brought up" (E/CN.4/1985/64, Annex II, p. 1).

60 La Comisión de Derechos Humanos de las Naciones Unidas decidió, a propuesta de la representación polaca (E/CN.4/1324), en su 1479 Sesión crear un Open-ended Working Group para tratar la cuestión de la Convención sobre los Derechos del Niño. Este grupo de trabajo tuvo sus primeras reuniones durante los meses de febrero y marzo de 1979. En su primer encuentro oficial Mr. Adam Lopatka (Polonia) fue elegido como presidente del mismo.

61 E/CN.4/1986/39, párr. 49.

$62 \mathrm{CRC} / \mathrm{C} / 58,20$ de noviembre de 1996, p. 16. 
al marcar las líneas directrices que deben seguirse para dar cuenta del estado de implementación del artículo $8^{\circ}$-preservación de la identidad- se guarda silencio al respecto, es decir, para nada se menciona la cuestión del género ${ }^{63}$.

Tuvo que aguardarse hasta el segundo decenio del siglo XXI para que el Comité ginebrino empezara a tomar en consideración, o mejor dicho a dar visibilidad, a la particular situación de los niños, niñas y adolescentes trans*, y ello sucedió al amparo tanto del artículo $2^{\circ}$ (derecho a la no discriminación), como, y en menor medida, del ya mentado artículo $8^{\circ}$ (derecho a la identidad), y accesoriamente de los artículos $3^{\circ}$ (principio del interés superior del niño/a) y 12 (derecho del niño/a a ser escuchado) todos ellos de la CDN ${ }^{64}$.

Tal circunstancia queda especialmente reflejada en las observaciones finales elaboradas por el Comité de los Derechos del Niño frente a los informes iniciales y periódicos presentados por los Estados Partes en virtud del artículo 44 de la CDN. De su análisis pormenorizado constatamos cómo no ha sido hasta el año 2014 que el Comité ginebrino ha empezado a mostrar su particular interés y preocupación por la realidad vivida por los niños, niñas y adolescentes que son lesbianas, gays, bisexuales y transgénero. Así, en las observaciones generales previas al año 2014, al hacerse referencia a las particulares medidas que deben adoptar los Estados Partes para combatir y prevenir la discriminación contra los niños y niñas pertenecientes a grupos vulnerables, no se mencionan expresamente dentro de esa categoría ni la orientación sexual ni la identidad de género, cosa que sí sucede de manera reiterada a partir de la citada fecha ${ }^{65}$.

Asimismo, encontramos múltiples Ilamadas al reconocimiento y respeto del derecho a la identidad de los niños, niñas y adolescentes trans* en los últimos Comentarios Generales elaborados por el Comité de los Derechos del Niño. En efecto, tanto en la Observación General № 14 (2013), sobre el derecho del

\footnotetext{
63 Lo mismo sucede en el documento del Comité de los Derechos del Niño que contiene las orientaciones generales respecto de la forma y el contenido de los informes que han de presentar los Estados Partes con arreglo al apartado a) del párrafo 1 del artículo 44 de la Convención sobre los Derechos del Niño. CRC/C/5, 30 de octubre de 1991, p. 4.

${ }^{64}$ Idéntica línea parece haber adoptado el legislador chileno. Así, en el proyecto de ey que establece el sistema de garantías de los derechos de la niñez, aprobado por la Cámara de Diputados (Oficio № 13.289, de 2 de mayo de 2017), se hace mención expresa al derecho a la identidad de género tanto en el artículo 19, que desarrolla de manera particular el propio derecho a la identidad, como en el artículo $9^{\circ}$, en el que se estipula que "ningún niño/a podrá ser discriminado en forma arbitraria en razón de...su orientación sexual, identidad de género, expresión de género, características sexuales.".

65 Ver en este sentido las Observaciones finales del Comité de los Derechos del Niño (todas ellas emitidas dentro del período 2014-2017) sobre los informes presentados por Eslovaquia, Perú, Chile, Reino Unido, Irlanda, Francia, Polonia, Suecia, Colombia, Suiza, Hungría, Portugal y Rusia.
} 
niño a que su interés superior sea una consideración primordial ${ }^{66}$, como en la Observación General № 15 (2013), sobre el derecho del niño al disfrute del más alto nivel posible de salud ${ }^{67}$, y más recientemente en la Observación General № 20 (2016), sobre la efectividad de los derechos del niño/a durante la adolescencia, se contienen referencias directas y explícitas a la especial protección que merecen la infancia y la adolescencia trans*68.

Finalmente, y no por ello menos trascendente, consideramos también importante traer a colación el último pronunciamiento del Comité de los Derechos del Niño junto a otros mecanismos de derechos humanos regionales y de las Naciones Unidas sobre la materia, del pasado 16 de mayo de 2017, concretamente se trata de la Declaración emitida en conmemoración del Día Internacional contra la Homofobia, Transfobia y la Biofobia ${ }^{69}$, en que se exhorta a los Estados a que faciliten el reconocimiento legal rápido, transparente y accesible de la identidad de género, sin condiciones abusivas, garantizando los derechos humanos de todas las personas, incluidas las jóvenes, y respetando las decisiones libres e informadas y la autonomía corporal ${ }^{70}$.

Pues bien, tomando en consideración esa línea evolutiva, de visibilización, seguida por el Comité de los Derechos del Niño, trataremos, acto seguido, de resolver la cuestión acerca de quién ostenta realmente la titularidad del derecho a la identidad de género, para, a continuación, centrarnos en aspectos vinculados con el ejercicio de ese mismo derecho cuando su titular sea una persona menor de edad ${ }^{71}$.

\footnotetext{
${ }^{66}$ CRC/C/GC/14, de 29 de mayo de 2913, párr. 55.
}

${ }^{67}$ CRC/C/GC/15, de 17 de abril de 2013, párr. 2 y 8. El Comité de los Derechos del Niño, en primer término, interpreta el derecho del niño/a a la salud, definido en el artículo 24 de la CDN, como un derecho inclusivo que no solo abarca la prevención oportuna y apropiada, la promoción de la salud y los servicios paliativos, de curación y de rehabilitación, sino también el derecho del niño/a a crecer y desarrollarse al máximo de sus posibilidades y vivir en condiciones que le permitan disfrutar del más alto nivel posible de salud; $y$, acto seguido, Ilama a los Estados a que respeten la orientación sexual, la identidad de género y el estado de salud de los niños, niñas y adolescentes.

${ }^{68}$ Cfr. CRC/C/GC/20, de 6 de diciembre de 2016, párr. 33 y 34.

69 Disponibleen: http://www.ohchr.org/SP/NewsEvents/Pages/DisplayNews.aspx?NewsID=21622\&LangID=S (fecha consulta: 26 de febrero de 2018)

70 En un sentido prácticamente idéntico ya se había pronunciado el Comité de los Derechos del Niño en sendas Declaraciones de los años 2015 y 2016 aprovechando la celebración del Día Internacional contra la Homofobia, Transfobia y la Biofobia. Disponibles ambas declaraciones en:

http://www.ohchr.org/SP/NewsEvents/Pages/DisplayNews.aspx?NewsID=19956\&LangID=S (2016) http://www.ohchr.org/SP/NewsEvents/Pages/DisplayNews.aspx?NewsID=15941\&LangID=S (2015) (fecha consulta: 26 de febrero de 2018)

71 Tal y como señala Lobera, es importante señalar lo relevante que resulta que el reconocimiento de derechos sea complementado por una teoría de la autonomía, que haga posible el ejercicio individual de aquéllos, pues conceder titularidad sin autonomía de ejercicio, nos vuelve a situar en el mismo 


\subsection{Titularidad y ejercicio del derecho a la identidad de género}

El derecho de la infancia y la adolescencia como disciplina autónoma es de reciente aparición, apenas data de finales del siglo pasado. En general, si bien es cierto que tras la aprobación y entrada en vigor de la Convención sobre los Derechos del Niño se viene reconociendo a las niñas, niños y adolescentes como sujetos de derecho, no es menos cierto que, a pesar de esos avances normativos, la infancia y la adolescencia continúan siendo, en gran medida, completamente invisibles a los ojos de nuestra sociedad ${ }^{72}$.

Advertida esta circunstancia, uno de los ámbitos en que, precisamente, toma mayor relevancia la afirmación esgrimida up supra es el de los derechos de la personalidad, dentro del cual se circunscribe, precisamente, el derecho a la identidad -en todas sus manifestaciones ${ }^{73}$. En efecto, tradicionalmente, se consideró a las personas que todavía no habían alcanzado la mayoría de edad como sujetos absolutamente incapaces de poder participar, ya sea directa o indirectamente, en la toma de decisiones vinculadas con el desarrollo integral de su personalidad. De esta forma, la persona menor de edad era considerada como un mero objeto pasivo de intervención, y, en consecuencia, debía actuar y consentir por él su representante lega ${ }^{74}$.

Ahora bien, el tratamiento legal irrogado a estas situaciones empezó a experimentar un cambio sustancial de tendencia a partir de finales del pasado siglo. El punto de inflexión de esta metamorfosis vino provocado por el advenimiento de una nueva filosofía acerca de la verdadera naturaleza de los derechos de la personalidad del individuo -en nuestro caso, una persona menor de edad-, no susceptibles, por definición, de representación legal ${ }^{75}$.

Concretamente, tal y como manifiesta la doctrina civil chilena, los niños, niñas y adolescentes son titulares de todos los derechos humanos, incluido el derecho a la identidad ${ }^{76}$. Ello vino a ser ratificado por la Corte Interamericana de Derechos Humanos al señalar que "la identidad personal está íntimamente ligada a la persona en su individualidad específica y vida privada, sustentadas ambas en una experiencia histórica y biológica, así como en la forma en que

punto de partida en que nos encontrábamos cuando los derechos no les eran reconocidos a las niñas, niños y adolescentes. Confróntese, LOBERA (2009), pp. 11-55. En ese mismo sentido se pronuncian SWANN y HeRBERT (2009), pp. 38-52.

72 RAMiro (2015), pp. 80-116; GAItÁn (2014), pp. 63-93; y Fortin (2008), pp. 55-65.

73 De Lama (2006), pp. 45-56; Bartolomé (2015), pp. 80-104; y Lathrop (2017), pp. 92-93.

${ }^{74}$ Ruiz (2009),pp. 81-82; y García (2012),p. 99.

75 Ravetllat (2017), pp. 30-44.

${ }^{76}$ ESPejo y Lathrop (2015), p. 411. 
se relaciona dicho individuo con los demás, a través del desarrollo de vínculos en el plano familiar y social. Es por ello que la identidad, si bien no es un derecho exclusivo de los niños y niñas, entraña una importancia especial durante la niñez"77.

Sin ir más lejos, el propio Proyecto de Ley que establece el Sistema de Garantías de los Derechos de la Niñez, aprobado por la Cámara de Diputados (Oficio No 13.289, de 2 de mayo de 2017) en su artículo 19 reconoce el derecho de todo niño/a "a preservar y desarrollar su propia identidad e idiosincrasia, incluida su identidad de género".

Es posible que la niña, niño o adolescente tenga limitada su capacidad de ejercicio en la toma de ciertas decisiones -en particular en el ámbito patrimonial-, pero desde luego, y siempre, por supuesto, atendiendo a su edad y estado de madurez, ostenta capacidad y autonomía para definir su propia identidad. Nadie más que la persona menor de edad sabe lo que siente, cómo se siente, quién es y cuál es su verdadero " $\mathrm{yo}^{\prime \prime 78}$. Nadie, ni progenitores, ni familia, ni profesionales, ni instituciones se pueden otorgar el derecho de reprimir, corregir, castigar o modificar su identidad, pues ello supone atentar directamente contra el desarrollo integral de su personalidad. Aceptar al niño, niña y adolescente como una persona autónoma no implica, en ningún caso, cuestionar ni poner en entredicho la autoridad de los adultos, sino reconocer su derecho a estar presentes, a expresar lo que sienten, siempre por supuesto en atención a sus características evolutivas, en la toma de aquellas decisiones que les afecten y enfatizando, en todo caso, que el rol que tiene el adulto - progenitores, familia, profesionales, instituciones- es el de llevar a cabo una misión de acompañamiento, conducción, promoción y educación ${ }^{79}$. En otras palabras, colaborar en la búsqueda del ámbito donde se han de encontrar y desarrollar a sí mismos.

Es difícil que una persona menor de edad afirme abiertamente ser trans* (o que lo manifieste un adulto en su representación), en la medida en que nuestro sistema jurídico continúa percibiendo mayoritariamente a la infancia y la adolescencia como unos seres inmaduros e incompletos, de manera que no se les

77 Corte Interamericana de Derechos Humanos, Fondo, Reparaciones y Costas. Sentencia de 27 de abril de 2012, Caso Forneron e hija vs. Argentina, párrafo 123.

78 Tal y como sostienen en Brill y Pepper, la identidad de género surge al mismo tiempo que las niñas y niños están aprendiendo a hablar y que empiezan a entender y nombrar el mundo que les rodea, por lo que es frecuente que alguno de estos niños y niñas traten de expresar lo que les pasa desde muy pronto. Estos primeros intentos de comunicación puede que se tomen en broma porque parezcan graciosos, como una confusión temporal, o simplemente parezcan una fase pasajera. Esta actitud adulta ignora el esfuerzo comunicativo de una persona muy joven, que no encuentra la interlocución que necesita. Confróntese, Brill y PePPER (2008), pp. 16-22.

79 Ravetllat (2016), pp. 504; y Ravetllat y Sanabria (2016), pp. 88-89. 
considera capaces, por sí solos, de conocer o afirmar sus vivencias de género. Es precisamente esta consideración de estar en proceso la que hace que las personas menores de edad estén especialmente controladas, vigiladas con respecto a sus manifestaciones de identidad, convirtiéndose en una verdadera amenaza ${ }^{80}$.

Efectuadas estas consideraciones generales acerca del reconocimiento progresivo del derecho de autonomía del individuo - principio de la capacidad progresiva- y su tratamiento jurídico, procederemos, finalmente, a enumerar algunas de las principales situaciones que, entendemos, mayor número de controversias generan en la praxis, tanto a nivel social como jurídico, cuando el sujeto involucrado activamente en ellas es una persona menor de edad. La posibilidad de instar la utilización de su nombre social (en la escuela o en el centro de salud), o de solicitar la rectificación registral conforme a su identidad de género, o incluso el pedir un determinado tratamiento hormonal, representan tan solo algunos de esos ámbitos de posible intervención autónoma de los adolescentes que provocan un sinfín de interrogantes, a los que trataremos de dar cumplida respuesta.

\section{Los derechos de los y las estudiantes trans* en el ámbito educativo}

En el contexto educativo, nos encontramos con la reciente y bien intencionada, aunque a nuestro entender limitada, Orden de la Superintendencia de Educación $N^{\circ}$ 768, de 27 de abril de 2017, relativa a los derechos de las niñas, niños y estudiantes trans en el ámbito de la educación.

Este documento, tras enumerar los principios orientadores para la comunidad educativa respecto a las niñas, niños y estudiantes trans*; identificar los derechos que asisten a este grupo de alumnos y alumnas; $y$, determinar cuáles son las obligaciones que recaen sobre los sostenedores y directivos de los establecimientos escolares, focaliza toda su atención en el procedimiento que debe seguirse para instar el reconocimiento de la identidad de género en el seno de un establecimiento educacional.

Pues bien, la citada Orden de la Superintendencia de Educación al fijar ese procedimiento tan solo legitima activamente para solicitar tal reconocimiento, así como las medidas de apoyo y adecuaciones curriculares pertinentes, "al padre, madre, tutor/a legal y/o apoderado de aquellas niñas, niños y estudiantes trans, como también el o la estudiante, en caso de contar con la mayoría de edad establecida en la legislación nacional". Parece, pues, que la autoridad competente, una vez más, se olvida del papel activo que las propias personas menores de edad pueden ejercer, siempre de conformidad con su edad y raciocinio, en la

80 Castañeda (2014), pp. 59-61. 
autodeterminación de sus derechos, en este caso el de su identidad de género. Idéntica desconfianza parece cernirse sobre las niñas, niños y adolescentes trans* cuando la misma Orden de la Superintendencia de Educación prevé que deben ser única y exclusivamente "el padre, madre, apoderado, tutor/a legal o el o la estudiante en caso de contar con la mayoría de edad" los que insten el uso del nombre social, con independencia del nombre legal que conste en la partida de nacimiento, en todos los espacios educativos.

Pareciera como si la Superintendencia, sin conseguir superar definitivamente la lectura de marcado tinte proteccionista que desde antaño ha venido informando y caracterizando el tratamiento social, educativo y legal que la infancia y la adolescencia han recibido, no logre hacer efectivo y real uno de los derechos que asisten a la niñez y la adolescencia trans*, y que la propia Orden N 768 enumera, cual es el "derecho a participar, a expresar su opinión libremente y a ser escuchados en todos los asuntos que les afectan, en especial cuando tienen relación con decisiones sobre aspectos derivados de su identidad de género". Esto, a lo que nos lleva, es a terminar definiendo los contornos de ese derecho desde el punto de vista, o la zona de confort, de los adultos ${ }^{81}$.

A mayor abundamiento, y reforzando nuestra argumentación, también cabe citar las Orientaciones para la inclusión de las personas lesbianas, gays, bisexuales, trans e intersex en el sistema educativo chileno, elaboradas por la Unidad de Inclusión y Participación Ciudadana del Ministerio de Educación (abril, 2017). Efectivamente, este documento hace referencia explícita al principio de autonomía progresiva (artículo $5^{\circ}$ de la Convención sobre los Derechos del Niño) indicando que "las niñas, niños y estudiantes tendrán progresivamente la facultad de ejercer sus derechos de acuerdo a la evolución de sus facultades, edad y madurez, y en base al acompañamiento y guía que realicen sus padres, madres, apoderado/a o tutor/a legal, confiriéndoles progresivamente mayor protagonismo en la definición de su identidad" ${ }^{\prime 2}$.

\section{Los derechos de las niñas, niños y adolescentes trans* en el ámbito registral}

El Proyecto de Ley de Identidad de Género establece que en Chile la transexualidad es "una realidad social que requiere una respuesta del legislador, para que la inicial asignación registral del sexo y del nombre propio pueda ser modificada, con la finalidad de garantizar el libre desarrollo de la personalidad y la dignidad de las personas cuya identidad de género no se corresponde con

81 Instituto Nacional de Derechos Humanos (2017), pp. 74-75.

82 Unidad de Inclusión y Participación Ciudadana. Ministerio de Educación (2017), p. 13. 
el sexo con el que inicialmente fueron inscritas". Esta ley parece, pues, que permitirá el cambio de nombre y sexo civil sin necesidad de cirugía de reasignación genital, tratamiento hormonal o informe psiquiátrico alguno. Ahora bien, mientras que el mentado texto legal no se convierta en una realidad normativa, la posibilidad de proceder al cambio registral de nombre y sexo sigue quedando en manos de los órganos judiciales competentes en la materia, sin que, por cierto, se esté siguiendo un criterio homogéneo acerca de los requisitos exigidos para su procedencia ${ }^{83}$.

Efectivamente, tras una línea jurisprudencial inicial tendente a exigir necesariamente la intervención quirúrgica de reasignación para autorizar el cambio de sexo en la partida de nacimiento registral ${ }^{84}$, parece que durante los últimos años las Cortes de Apelaciones están gestando un cambio de dirección (siguiendo

83 Idéntica disparidad se da en España al referirnos a la posibilidad de lograr el cambio registral de sexo y nombre de personas menores de edad trans*. Ello queda ejemplificado en los dos casos relatados a continuación. El primero hace referencia a las resoluciones judiciales adoptadas por las magistradas titulares del Registro Civil de Mislata (Valencia) y de Valencia. En ellas se autoriza a sendos menores de edad trans* a cambiar el sexo con el que figuran en el Registro Civil, y por tanto también en la cédula de identificación, sin esperar a la mayoría de edad y sin necesidad de acomodar sus características físicas al género reclamado. El segundo es el caso de una joven de catorce años que ha presentado en apoyo de su solicitud escritos médicos y el acompañamiento de sus progenitores. Tras recibir negativas a su reclamación de cambio de sexo registral en diversas instancias, su caso llegó al Tribunal Supremo, órgano jurisdiccional que tomando como referencia la Ley $N^{\circ} 3 / 2007$, de 15 de marzo, que exige la mayoría de edad para el cambio de la identidad sexual en el Registro Civil, se cuestiona la constitucionalidad de tal limitación cuando se trata "de un menor con suficiente madurez que realiza una petición seria por encontrarse en una situación estable de transexualidad", y eleva su duda al Tribunal Constitucional, instancia ésta en la que se encuentra el caso pendiente de respuesta.

84 Sentencia de la Corte de Apelaciones de Santiago, rol № 2541-2009, de 25 de junio de 2009, conoció el caso en que una transgénero femenina solicitó cambio de nombre y sexo registral, lo que le había sido negado en primera instancia, aduciendo que no se habían acreditado las causales que autorizan el cambio de nombre ni se había probado cirugía de reconstrucción genital. El juez de primera instancia señaló que debido a que el artículo 31 de la Ley de Registro Civil prohíbe la contradicción entre el nombre y el sexo de una persona, no se podía acceder a la petición. Por su parte, la Corte modificó parcialmente la resolución concediendo el cambio de nombre, pero negando la modificación de sexo. Respecto de lo primero, la Corte consideró probado que, desde el punto de vista psicológico, la solicitante era mujer, y por ende,..." resulta evidente para este tribunal que su nombre, como atributo de la personalidad y componente esencial de la identidad de una persona, que determina su relación con la sociedad y que lo distingue frente a los demás, no puede ser uno de carácter masculino, ya que esto impide que el peticionario desarrolle su verdadera personalidad y se desenvuelva frente a los otros conforme a la condición sexual que reconoce para sí mismo y a través de la cual asume su proyección en la vida". Así, la Corte estimó que concurrían a su favor las causales (a) y (b) del artículo $1^{\circ}$ de la Ley $N^{\circ} 17.344$ de Cambio de Nombre, al tiempo que estimó que dicho cambio de nombre era consistente con el artículo 31 de la Ley de Registro Civil, que proscribe imponer a una persona un nombre equívoco respecto del sexo. Sin embargo, no otorgó el cambio de sexo, pues consideró "razonable exigir que el solicitante se someta previamente a una intervención para adecuar sus órganos genitales externos al sexo realmente vivido". 
lo prescrito por la Relatoría sobre los Derechos de las Personas LGBTI, de la Comisión Interamericana de Derechos Humanos). El fundamento radica en que si actualmente la legislación civil chilena permite el cambio de nombre y, a la vez, prescribe que el nombre debe ajustarse al sexo, entonces se concluye que todo cambio de nombre debe respetar la realidad que le sirve de parámetro y, si tal realidad se encuentra erradamente consignada, entonces debe ser corregido el instrumento respectivo, junto a la modificación nominativa ${ }^{85}$.

Parece, a nuestro entender, que esta nueva línea jurisprudencial de los tribunales chilenos es coherente con el desarrollo internacional del derecho a la identidad de género. Así, la no autorización de la modificación registral del sexo se considera como fuente potencial de un menoscabo moral y material del individuo, a la par que impide su realización personal, el libre desarrollo de su personalidad y lo afecta gravemente en su dignidad como ser humano. Es más, supeditar la reasignación sexual, a la previa realización de una intervención quirúrgica, implicaría una seria incongruencia, puesto que sería quedarnos en una visión reduccionista que equipara sexo con género, con solo una de sus exteriorizaciones, en este caso la presencia de órganos genitales externos, en desmedro de la verdadera identidad del sujeto ${ }^{86}$.

Si bien es cierto que la Ley $N^{0} 17.344$ jamás tuvo como uno de sus objetivos específicos la regulación del cambio de nombre y/o sexo registral de las personas trans*, no es menos cierto que ante el vacío normativo generado en

85 En este sentido se pronuncian, por ejemplo, la sentencia de la Corte de Apelaciones de Iquique, rol № 496-2014, de 26 de noviembre de 2014; Sentencia de la Corte de Apelaciones de Santiago, rol N ${ }^{\circ}$ 12571-2015, de 27 de enero de 2016; sentencia de la Corte de Apelaciones de Valparaíso, rol № 949-2013, de 23 de julio de 2013; Sentencia de la Corte de Apelaciones de Valparaíso, rol № V-1452014, de 12 de enero de 2014. Por su parte, Lathrop analizó cuarenta causas con sentencia de término. En treinta y tres casos se acogía la solicitud de cambio de nombre y sexo. Por su parte, solo cuatro de ellas rechazaban la petición, y tres la acogían parcialmente (se accedía solo a cambio de nombre, por ejemplo). LATHROP (2015) pp. 321-322.

${ }^{86}$ Cfr. Corte de Apelaciones de Santiago, rol No 12571-2015, de 27 de enero de 2016. Reproduce esta línea interpretativa la propia Corte de Apelaciones de Santiago, rol № 13213-2016, de 13 abril de 2017, añadiendo además que "la calidad de transexual o transgénero, dada por su complejidad psico-anatómica genera un altísimo costo emocional, social y económico para quien la vive, los dos primeros se aprecian como producto de la incomprensión del medio social frente a la condición de la solicitante y las consecuentes actitudes de discriminación y trato no acordes a la realidad que se vivencia en todo ámbito, desde la formación escolar, profesional, laboral y social. El económico se produce por la exigencia -no legal- de tener que someterse para justificar estas solicitudes de rectificación a dispendiosas, desgastantes e invasivas transformaciones corporales, tratamientos hormonales y reeducaciones asociadas al modo de actuar del género que se percibe como propio e ir reemplazando los aprendizajes forzosos del asumido como anatómicamente obligatorio, con el que dicho sea de paso no se tiene pertenencia alguna, aspecto económico que de por sí ya sería discriminatorio frente a aquellos transgéneros que no tengan la capacidad económica de invertir cuantiosos recursos en tales iniciativas, postergando de facto sus derechos a la identidad". 
ese sector del ordenamiento jurídico debemos acudir a sus disposiciones. Para el caso de las personas menores de edad trans* no debiera presentarse problema alguno, ya que el sexo que muestran estos niños, niñas o adolescentes en la realidad extrarregistral, que ha de predominar sobre la registral cuando ésta sea errónea, es el que se corresponde a su identidad de género (principio de exactitud registral). Por ello, el nombre (social) usado y solicitado por estas persones menores de edad no induce a error en cuanto a su sexo, sino que, por el contrario, el nombre que figura en la partida de nacimiento registral es el que suscita tal confusión. Por ende, el no permitir la adaptación del sexo inscrito originariamente en el Registro Civil al nombre y género efectivamente sentido, es lo que sería contrario a las previsiones del artículo 31 de la Ley $\mathrm{N}^{\circ} 4.808$, sobre Registro Civil, y no precisamente lo contrario.

Añadir a lo anterior, que la no admisión de ese cambio de nombre y sexo registral estaría perjudicando gravemente el desarrollo integral de la personalidad del niño o la niña, o, en otros términos, supondría un menoscabo moral o material del mismo. De este modo, la causal a) del inciso segundo del artículo $1^{\circ}$ de la Ley $N^{\circ} 17.344$, entra en escena y nos habilita para instar ese cambio ante el juez de letras en lo civil competente. Ello sin perjuicio, atendiendo a la edad de la persona menor y al momento temporal a partir del cual empezó a ser conocido por su nombre social, que también pueda instarse la causal b) del propio precepto (cuando el solicitante haya sido conocido por más de cinco años con nombre distinto al inscrito $)^{87}$.

Para cerrar este apartado, simplemente afirmar que estimamos que sería oportuno, a tenor del principio de la capacidad progresiva, que la futura Ley de Identidad de Género, incorporara la idea del ejercicio autónomo de este derecho de la personalidad por parte de las personas menores de edad. Para ello somos partidarios de introducir una edad presuntiva -presunción iuris tantum- de madurez (concretamente los catorce años), llegada la cual, salvo prueba en contrario, se entienda que el adolescente puede instar por sí el mentado cambio registral de nombre y sexo ${ }^{88}$. Por debajo de esa edad se entenderá

\footnotetext{
${ }^{87}$ No se trata de un capricho ni de una decisión arbitraria de las personas menores de edad, ni de los progenitores. No es una veleidad repentina. Las niñas y niños trans* tienen muchas maneras de reafirmar su identidad, de mostrar el descontento y el malestar de que se les trate conforme a un género que no es el suyo. Asimismo, la sentencia del TEDH de 10 de marzo de 2015, Y.Y. c/Turquía (párrafo 59), reproduciendo lo establecido previamente en el caso Van Kück vs. Alemania, sentencia de 12 de septiembre de 2003, considera inadmisible que pueda calificarse de capricho la circunstancia de que una persona decida someterse a una intervención de reasignación de género (párrafo 115).

88 Nos inclinamos por los catorce años de edad, considerando que el artículo 16.3 de la Ley $N^{\circ}$ 19.968, de Tribunales de Familia, del año 2004, distingue entre las categorías niño/a y adolescente, utilizando precisamente ese momento temporal. Así, los niños/as, como regla general, son vistos como seres con capacidad limitada para el ejercicio autónomo de los derechos, se sobreentiende
} 
que tal solicitud debe ser realizada, salvo que se acredite que la persona es lo suficientemente madura, a través de sus representantes legales o de quien lo tenga bajo su cuidado ${ }^{89}$.

\section{Los derechos de las niñas, niños y adolescentes trans* en el ámbito sanitario}

A pesar de ser abordado en último término, es particularmente importante el tratamiento que se dé a los niños, niñas y adolescentes trans* en el ámbito sanitario, para que estos logren alcanzar su pleno e íntegro desarrollo como individuos.

Todas las personas, incluidas por supuesto las que no han alcanzado todavía su mayoría de edad, tienen derecho al más alto nivel de disfrute de salud física y mental, incluida la salud sexual y reproductiva, sin discriminación alguna por razón de su identidad de género sentida o expresada ${ }^{90}$.

Es por ello que los establecimientos de la red asistencial que brinden atención a la salud de un niño, niña o adolescente trans*, en sus distintas modalidades y especificidades, deben asegurar el uso del nombre social con el que dicha persona se identifica (con independencia del nombre legal). En consecuencia, tal y como estipula la Circular N 34, de 13 de septiembre de 2011, del Ministerio de Salud ${ }^{91}$, se espera que el nombre social sea usado durante el trato y la atención, así como también en los diversos registros destinados a la identificación social del individuo. Esto se aplica tanto para la ficha clínica como para la solicitud de exámenes, procedimientos, prescripción de medicamentos y brazaletes identificativos $^{92}$. Asimismo, la identificación verbal, prosigue la mentada circular, debe ser a través del nombre social de la persona menor de edad trans*.

extrapatrimoniales; $y$, por el contrario, los adolescentes son tildados como individuos con capacidad de ejercicio autónomo de los derechos de la personalidad. En este sentido se pronuncia también BARCIA (2013), pp. 3-52.

89 Lathrop y Espejo se pronuncian en un sentido similar, si bien ellos se muestran partidarios de que el legislador no establezca un límite de edad formal, sino que se sujete más bien a criterios de determinación de madurez. Confróntese, EsPejO y LATHrop (2015), p. 412. Nosotros consideramos prudente introducir una presunción de madurez a los catorce años, que, por supuesto admite prueba en contrario en ambos sentidos, para dotar al sistema, o más bien a quien corresponda tomar la decisión (juez o funcionario del Registro Civil), de mayor seguridad jurídica.

90 Instituto Nacional de Derechos Humanos (2017), pp. 71-73.

91 Estas instrucciones fueron reiteradas de nuevo por la Circular N $N^{\circ} 21$, de 14 de junio de 2012, del Ministerio de Salud.

92 Para ser más exactos, la Circular establece que "todos los registros derivados de la atención de salud deben contemplar en primer lugar el nombre legal de la persona (consignado en la cédula de identificación) y en segundo lugar, el nombre social con el cual dicha persona se identifica". 
Para los casos en que los niños o niñas deban ser hospitalizados, el equipo de salud debiere tomar en consideración el género sentido por la persona menor de edad a la hora de serle asignada cama, así como hacer uso de su nombre social al facilitar información sobre su estado de salud.

En otro orden de cosas, tomar también en consideración que para no pocos adolescentes trans*, el tratamiento bloqueador y el hormonal forman parte de una serie de herramientas que, si lo estimaren oportuno, pueden utilizar, para hacer efectivos, o facilitar al menos, el respeto de sus derechos fundamentales: dignidad, integridad moral y, en definitiva y especialmente, su salud integral. Precisamente por ello debiera reconocerse de manera expresa el derecho a recibir ese tratamiento para el bloqueo hormonal al inicio de la pubertad para evitar el desarrollo de caracteres sexuales secundarios no deseados; y el derecho a recibir tratamiento hormonal cruzado en el momento adecuado de la pubertad para favorecer que su desarrollo corporal se corresponda con el de las personas de su edad, a fin de propiciar el desarrollo de caracteres sexuales secundarios deseados.

Bajo nuestro punto de vista, los criterios mínimos que las personas debieran cumplir para iniciar este tipo de tratamientos son los citados a continuación: que el o la adolescente presente cierta estabilidad por lo que respecta al género sentido; que haya prestado su consentimiento informado, ya sea por sí, atendiendo a su edad y estado de madurez, o mediante sus progenitores, tutores u otros cuidadores implicados; $y$, en último término, en caso de presentar el o la adolescente algún problema particular (psicológico, médico o social) que pueda interferir en el tratamiento, que este haya sido debidamente abordado, de manera que la situación de la persona sea lo suficientemente estable para iniciar el tratamiento.

La negativa de los representantes legales del adolescente a autorizar tratamientos relacionados con la identidad trans* o a que se establezca preventivamente un tratamiento de inhibición del desarrollo hormonal, debería poder ser recurrida ante la autoridad judicial. En todo caso, debe resolverse la cuestión atendiendo al principio del interés superior de la persona trans* menor de edad.

\section{Algunas conclusiones}

En el presente artículo hemos evidenciado que las niñas, niños y adolescentes trans* no presentan ningún problema médico, psicológico o psiquiátrico. Por el contrario, los problemas que se les pudieran presentar guardan relación directa con la sociedad que no los admite y los excluye, los segrega y los estigmatiza.

Asimismo, también hemos constatado cómo el Comité de los Derechos del Niño está siguiendo una línea evolutiva en esta materia tendente a visibilizar, cada vez en mayor medida, la realidad de las niñas, niños y adolescentes trans*. 
Tal circunstancia se está suscitando al amparo tanto del artículo $2^{\circ}$ (derecho a la no discriminación), como, y en menor medida, del artículo $8^{\circ}$ (derecho a la identidad), y accesoriamente de los artículos $3^{\circ}$ (principio del interés superior del niño/a) y 12 (derecho del niño/a a ser escuchado) todos ellos de la Convención sobre los Derechos del Niño.

Finalmente, y por lo que a la titularidad y ejercicio del derecho a la identidad (de género) se refiere cuando su titular es una persona menor de edad, consideramos que atendida su naturaleza, como derecho de la personalidad (inherente al sujeto desde el preciso instante de su nacimiento), el mismo es ostentado, tomando siempre en consideración la edad y estado de madurez, por las niñas, niños y adolescentes. En otras palabras, debe serles reconocida su capacidad y autonomía para definir su propia identidad, incluida, por supuesto, la de género. Aceptar a la niña, niño y adolescente como una persona autónoma no implica, en ningún caso, cuestionar ni poner en entredicho la autoridad de los adultos, sino reconocer su derecho a estar presentes, a expresar lo que sienten, siempre de forma acorde a sus características evolutivas, en la toma de aquellas decisiones que les afecten y enfatizando, en todo caso, que el rol que tiene el adulto (progenitores, familia, profesionales, instituciones) es el de llevar a cabo una misión de acompañamiento. En suma, colaborar en la búsqueda del ámbito donde se han de encontrar y desarrollar a sí mismos.

\section{Bibliografía CitADA}

Aparisi MiRalles, Ángela (2015): “Del igualitarismo al postfeminismo de género, al modelo de la igualdad en la diferencia", en Rivista Education Sciences and Society (vol. 7, № 1), pp. 37-49.

AmNeSTy INTERNATIONAL (2017): First, do no harm. Ensuring the rights of children with variations of sex characteristics in Denmark and Germany (London, Amnesty International).

Arjona Ledesma, Sheila (2016): Infancia con creatividad de género. Identidades no binarias, cuerpos transgresores y despatologización trans* (Granada, Universidad de Granada).

BalzA, Isabel (2009): "Bioética de los cuerpos sexuados: transexualidad, intersexualidad y transgenerismo", en Revista de Filosofía Moral y Política ( No 40), pp. 245-258.

Barcia LehmanN, Rodrigo (2013): "La capacidad extrapatrimonial de los niños y adolescentes conforme a sus condiciones de madurez", en Revista lus et Praxis (año 19, No 2), pp. 3-52.

BARTOlOmé Tutor, Aránzazu (2015): Los derechos de la personalidad del menor de edad. Su ejercicio en el ámbito sanitario y en las nuevas tecnologías de la información y comunicación (Cizur Menor, Thomson Reuters Aranzadi). 
BARUDY, Jorge (1998): El dolor invisible de la infancia. Una lectura ecosistémica del maltrato infantil (Barcelona, Ed. Paidós).

BRILL, Stephanie y PEPPER, Rachel (2008): The transgender child: a handbook for families and professionals (Berkley, Cleis Press).

Castañeda, Claudia (2014): "Childhood", en Transgender Studies Quarterly (vol. I. Nos. 1-2), pp. 59-61.

Comité de los Derechos del Niño (2016): Observación General № 20, de 6 de diciembre, sobre la efectividad de los derechos del niño durante la adolescencia, CRC/C/GC/20.

Comité de los Derechos del Niño (2013): Observación General № 14, de 29 de mayo, sobre el derecho del niño a que su interés superior sea una consideración primordial, CRC/C/GC/14.

Comité de los Derechos del Niño (2013): Observación General № 15, de 17 de abril, sobre el derecho del niño al disfrute del más alto nivel posible de salud, CRC/C/GC/15.

Comité de los Derechos del Niño (1996): Orientaciones generales respecto de la forma y el contenido de los informes que han de presentar los Estados Partes con arreglo al apartado b) del párrafo 1 del artículo 44 de la CDN, de 20 de noviembre, CRC/C/58.

Comité de los Derechos del Niño (1991): Orientaciones generales respecto de la forma y el contenido de los informes que han de presentar los Estados Partes con arreglo al apartado b) del párrafo 1 del artículo 44 de la CDN, de 30 de octubre, CRC/C/5.

De Lama Aymá Miralles, Alejandra (2006): "La protección de los derechos de la personalidad del menor de edad" (Valencia, Tirant lo Blanch).

Echávarri Vesperinas, María Orietta et al. (2015): "Aumento sostenido del suicidio en Chile: un tema pendiente", en Temas de la Agenda Pública. Centro de Políticas Públicas de la Facultad de Medicina de la Pontificia Universidad Católica de Chile ( $\left.N^{\circ} 79\right)$, pp. 6-8.

ElÓSEGUI ITXASO, María (1999): “La transexualidad. Jurisprudencia y argumentación jurídica" (Granada, Comares).

Espejo YaKsIC, Nicolás y Lathrop Gómez, Fabiola (2015): "Identidad de género, relaciones familiares y derechos de niños, niñas y adolescentes. Comentarios al proyecto de ley que reconoce y da protección al derecho a la identidad de género", en Revista de Derecho de la Universidad Católica del Norte (año 22, No 2), pp. 393-418.

FORTIN, Jane (2008): "Children as rights holders: awareness and skepticism" en Invernizz, Antonella y Williams, Jane (ed.): Children and citizenship (London, SAGE Publications), pp. 55-65. 
Fundación Todo Mejora (2016): Encuesta Nacional de Clima Escolar en Chile 2016. Experiencias de niños, niñas y adolescentes lesbianas, gays, bisexuales y trans en establecimientos educacionales (Santiago, Fundación Todo Mejora).

Gaitán Muñoz MiRalles, Lourdes (2014): De "menores" a protagonistas (Madrid, Impulso a la Acción Social).

García AlguaCiL, María José (2012): "Alcance de la autonomía de la voluntad del menor maduro: el camino de la incoherencia legislativa", en Boletín del Servicio de Estudios Registrales de Cataluña (№ 157), pp. 99-108.

Gauché Marchetti, Ximena (2014): “Análisis crítico de la Ley № 20.609, que establece medidas contra la discriminación, a la luz del derecho internacional de los derechos humanos y las convenciones de la OEA sobre discriminación de 2013", en Revista Chilena de Derecho y Ciencia Política (vol. 5, No 1), p. 11-58.

GaVILÁN MACíAs, Juan (2016): "Modelo sociocultural para la intervención en la transexualidad infantil" en Gallego, Aránzazu y Espinosa, María (eds.): Miradas no adultocéntricas sobre la infancia y la adolescencia. Transexualidad, orígenes en la adopción, ciudadanía y justicia juvenil (Granada, Ed. Comares), pp. 3-28.

Generelo, Jesús; Pichardo, J. Ignacio y Galofré, Guillem (2008): Adolescencia y sexualidades minoritarias. Voces desde la exclusión (Jaén, Alcalá Grupo Editorial).

Instituto Nacional de Derechos Humanos (2017): Informe anual. Situación de los Derechos Humanos en Chile (Santiago, Instituto Nacional de Derechos Humanos).

LATHROP, Fabiola (2015): "Identidad de género y relaciones de familia" en Vidal, Álvaro; Severin, Gonzalo; y Mejías, Claudia (eds.): Estudios de Derecho Civil X. Jornadas Nacionales de Derecho Civil, Valparaíso, 2014 (Santiago, Thomson Reuters), pp. 321-329.

LATHROP, Fabiola (2017): "Conflicto de derechos por exhumación de cadáver en juicios de filiación", en Revista lus et Praxis (año 23, № 1), pp. 91-126.

LÁZARO GonZÁlez, Isabel (2017): “La identidad de género a la luz de la Convención de los Derechos del Niño. Algunas reflexiones desde el interés superior del niño" en Bartolomé Tutor, Aránzazu (eds.): Menores e identidad de género. Aspectos sanitarios, jurídicos y bioéticos (Madrid, Sepín), pp. 73-93.

Lobera Palermo, Domingo (2009): “Niño, adolescente y derechos constitucionales: de la protección a la autonomía" en Justicia y Derechos del Niño (№ 11), pp. 11-55. 
López GuzmÁn, José (2016): Transexualismo y salud integral de la persona (Valencia, Tirant lo Blanch).

López Moratalla, Natalia (2012): "La identidad sexual: personas transexuales y con trastornos del desarrollo gonadal. No existen sexos, sólo roles: un experimento antropológico necesitado de la biotecnología", en Cuadernos de Bioética (vol. 23, № 2), pp. 341-371.

López SÁnchez, Félix (2013): "Identidad sexual y orientación del deseo en la infancia y la adolescencia", en AEPap, pp. 209-225.

Marcuello Franco, Ana Carmen y Elósegui Itxaso,María (1999): "Sexo, género, identidad sexual y sus patologías", en Cuadernos de Bioética (vol. 10, $\left.\mathrm{N}^{\circ} 39\right)$, pp. 459-477.

Ministerio de la Salud de la Nación Argentina (2017): Salud y adolescencias LGBTI. Herramientas de abordaje integral para equipos de salud (Buenos Aires, Ministerio de Salud de la Nación Argentina).

Missé, Miquel (2013): Guía para madres y padres de niñ@s con roles y comportamientos de género no-normativos (Barcelona, AMPGYL).

Organization for Economic Cooperation and Development (2015): Health at a glance. OECD Indicators (Paris, OECD Publishing).

Platero Méndez, Raquel (2014a): "La agencia de los jóvenes trans para enfrentarse a la transfobia", en Revista Internacional de Pensamiento Político (vol. 9), pp. 183-193.

Platero MÉndez, Raquel (2014b): Trans*exualidades. Acompañamiento, factores de salud y recursos educativos (Barcelona, Ediciones Bellaterra).

Puche Cabezas, luis; Moreno Ortego, Elena y Pichardo Galán, José Ignacio (2013): "Adolescentes transexuales en las aulas. Aproximación cualitativa y propuestas de intervención desde la perspectiva antropológica" en Moreno Cabrera, Octavio y Puche Cabezas, Luis (eds.): Transexualidad, adolescencias y educación. Miradas multidisciplinares (Madrid, Egales), pp. 189- 267.

Ramiro, Julia (2015): Ciudadanía e infancias. Los derechos de los niños en el contexto de la protección (Valencia, Tirant Humanidades).

RAMÓN FERNÁNDEZ, Francisca (2017): Menor y diversidad sexual. Análisis de las medidas de protección en el ordenamiento jurídico español para la identidad de género (Valencia, Universidad Politécnica de Valencia).

RavetLlat Ballesté, Isaac (2017): "El consentimiento informado de la persona menor de edad a los tratamientos e intervenciones médicas", en La Ley Derecho de Familia: Revista Jurídica sobre Familia y Menores ( $N^{\circ} 13$ ), pp. 30-44.

RavetLlat Ballesté, Isaac (2016): "La toma de decisiones de los progenitores en el ámbito sanitario: a vueltas con el interés superior del niño a propósito de 
la sentencia de la Corte Suprema de 3 de marzo de 2016", en Revista lus et Praxis (año. 22, No 2), pp. 499-512.

Ravetllat Ballesté, Isaac y Sanabria Moudelle, Claudia (2016): "La participación social de la infancia y la adolescencia a nivel municipal. El derecho del niño a ser tomado en consideración", en Revista Internacional de Investigación en Ciencias Sociales (vol. 12, No 1), pp. 87-102.

Ravetllat Ballesté, Isaac (2015): Aproximación histórica a la construcción sociojurídica de la categoría infancia (Valencia, Universidad Politécnica de Valencia).

Ruíz JIMÉNEZ, Juana (2009): "La capacidad del menor en el ámbito sanitario", en Pous de la Flor, María Paz (ed.): La capacidad de obrar del menor: nuevas perspectivas jurídicas (Madrid, Exlibris), pp. 75-92.

Sanz-Caballero, Susana (2014): "El Tribunal Europeo de Derechos Humanos y su respuesta al reto de la transexualidad: historia de un cambio de criterio", en American University International Law Review (vol. 29, № 4), pp. 831-868.

Solsona Pairó, Núria (2016): Ni princesas ni piratas. Para educar niños y niñas en libertad (Barcelona, Ed. Eumo).

SuESS, Aimar (2010): "Análisis del panorama discursivo alrededor de la despatologización trans: procesos de transformación de los marcos interpretativos en diferentes campos sociales" en Missé, Miquel y Coll-Planas, Gerard (eds.): El género desordenado. Críticas en torno a la patologización de la transexualidad (Barcelona, Egales), pp. 29-54.

Swann, Stephanie K. y Herbert, Sarah E. (2009): "Ethical issues in the mental health treatment of trans adolescents" en Mallon, Gerald P. (ed.): Social work practice with transgender and gender variant youth (New York, Roudledge), pp. 38- 52.

Unidad de Inclusión y Participación Ciudadana. Ministerio de Educación Chileno (2017): Orientaciones para la inclusión de las personas lesbianas, gays, bisexuales, trans e intersex en el sistema educativo chileno (Santiago, Ed. Ministerio de Educación).

Ventura, Rafael y VAz, Iván (2014): "La identidad transexual infantil. Estudio del caso Málaga en el País.com" en Libro de Actas del II Congreso Internacional de Comunicación y Género (Sevilla, Universidad de Sevilla), pp. 462-472.

\section{NORMAS CITADAS}

Convención sobre los Derechos del Niño (20/11/1989).

Ley No 4.808 (10/02/1930), Reforma la Ley sobre el Registro Civil. 
Ley $N^{\circ} 17.344$ (22/09/1970), Autoriza el Cambio de Nombres y Apellidos en los casos que indica.

Ley N No 19.968 (30/09/2004), Crea los Tribunales de Familia.

Ley uruguaya $N^{\circ} 18.620$ (25/10/2009), De la regulación del derecho a la identidad de género, cambio de nombre y sexo registral.

Ley argentina № 26.743 (23/06/2012), Ley de Identidad de Género.

Ley Nº 20.609 (24/07/2012), De medidas contra la discriminación.

Ley boliviana No 807 (21/05/2016), Ley de Identidad de Género.

Orden de la Superintendencia de Educación, del Ministerio de Educación de Chile No 768 (27/04/2017), relativa a los derechos de las niñas, niños y estudiantes trans en el ámbito de la educación.

Circular del Ministerio de Salud de Chile № 34 (13/09/2011), instruye sobre la atención de personas trans y fortalecimiento de la estrategia de hospital amigo a personas de la diversidad sexual en establecimientos de la red asistencial.

Circular del Ministerio de Salud de Chile № 21 (14/06/2012), reitera instrucción sobre la atención de personas trans en la red asistencial.

Circular del Ministerio de Salud de Chile № 18 (22/12/2015), instruye sobre ciertos aspectos de la atención de salud a niños y niñas intersex.

\section{JURISPRUDENCIA CITADA}

Leo Rocha con Circunscripción de Arica del Servicio del Registro Civil e Identificación (2014): Corte de Apelaciones de lquique, de 26 de noviembre de 2014 (recurso de apelación), rol № 496-2014.

Aranda con Circunscripción de Providencia del Servicio del Registro Civil e Identificación (2016): Corte de Apelaciones de Santiago, de 27 de enero de 2016 (recurso de apelación), rol № 12.571-2015.

Raveau con Circunscripción de Recoleta del Servicio del Registro Civil e Identificación (2017): Corte de Apelaciones de Santiago, de 13 de abril de 2017 (recurso de apelación), rol № 13.213-2016.

\section{JURISPRUDENCIA INTERNACIONAL}

Tribunal Europeo de Derechos Humanos.

Rees vs. Reino Unido (1986): Tribunal Europeo de Derechos Humanos, sentencia de 17 de octubre de 1986.

Cossey vs. Reino Unido (1990): Tribunal Europeo de Derechos Humanos, Sentencia de 27 de septiembre de 1990. 
B. vs. Francia (1992): Tribunal Europeo de Derechos Humanos, Sentencia de 25 de marzo de 1992.

X., Y. y Z. vs. Reino Unido (1997): Tribunal Europeo de Derechos Humanos, Sentencia de 22 de abril de 1997.

Sheffield y Horsham vs. Reino Unido (1998): Tribunal Europeo de Derechos Humanos, Sentencia de 30 de junio de 1998.

Cristine Goodwin vs. Reino Unido (2002): Tribunal Europeo de Derechos Humanos, Sentencia de 11 de julio de 2002.

I. vs. Reino Unido (2002): Tribunal Europeo de Derechos Humanos, Sentencia de 11 de julio de 2002.

Van Kück vs. Alemania (2003): Tribunal Europeo de Derechos Humanos, Sentencia de 12 de septiembre de 2003.

H. vs. Finlandia (2012): Tribunal Europeo de Derechos Humanos, Sentencia de 13 de noviembre de 2012.

Y. Y. vs. Turquía (2015): Tribunal Europeo de Derechos Humanos, Sentencia de 10 de marzo de 2015.

A. P. , Garçon, y Nicat vs. Francia (2017): Tribunal Europeo de Derechos Humanos, Sentencia de 6 de abril de 2017.

Corte Interamericana de Derechos Humanos.

Attala Riffo y niñas vs. Chile (2012): Corte Interamericana de Derechos Humanos, sentencia de 24 de febrero de 2012.

Fornerón e hija vs. Argentina (2012): Corte Interamericana de Derechos Humanos, sentencia de 27 de abril de 2012.

Duque vs. Colombia (2016): Corte Interamericana de Derechos Humanos, sentencia de 26 de febrero de 2016.

Opinión Consultiva OC/17 (2017), sobre identidad de género, e igualdad y no discriminación a parejas del mismo sexo, de 24 de noviembre de 2017. 
